No.1817

November 2021

\title{
Air pollution and innovation
}

Felix Bracht

Dennis Verhoeven 


\begin{abstract}
Existing estimates of the economic costs of air pollution do not account for its effect on inventive output. Using two weather phenomena as instruments, we estimate this effect in a sample of 1,288 European regions. A decrease in exposure to small particulate matter of $0.17 \mu \mathrm{g} / \mathrm{m} 3$ - the average yearly reduction in Europe - leads to $1.7 \%$ more patented inventions. After ruling out reallocation of human capital, inventor mortality and R\&D expenditures as drivers of the effect, we conclude that air pollution's harm to economic output increases by at least $10 \%$ when accounting for innovation.
\end{abstract}

Key words: air pollution, air quality, innovation, patent, productivity JEL: O30; Q53; O13

This paper was produced as part of the Centre's Growth Programme. The Centre for Economic Performance is financed by the Economic and Social Research Council.

We thank Dirk Czarnitzki, Hans Degryse, Tauhidur Rahman, Thomas Schaper, Steven Vanhaverbeke and Jesse Wursten for valuable comments and feedback. The resources and services used in this work were provided by the VSC (Flemish Supercomputer Center), funded by the Research Foundation Flanders (FWO) and the Flemish Government. Verhoeven gratefully acknowledges funding from the Research Foundation Flanders (FWO grant 1241520N) and the H2020 Framework Programme (Marie Skłodowska-Curie Action DIV_INV grant 844254)

Felix Bracht, KU Leuven. Dennis Verhoeven, KU Leuven, Bocconi University, ICRIOS, and Centre for Economic Performance, London School of Economics.

Published by

Centre for Economic Performance

London School of Economics and Political Science

Houghton Street

London WC2A 2AE

All rights reserved. No part of this publication may be reproduced, stored in a retrieval system or transmitted in any form or by any means without the prior permission in writing of the publisher nor be issued to the public or circulated in any form other than that in which it is published.

Requests for permission to reproduce any article or part of the Working Paper should be sent to the editor at the above address.

(c) F. Bracht and D. Verhoeven, submitted 2021. 


\section{Introduction}

Knowing the economic costs of air pollution is important for rational abatement policies (Landrigan et al., 2018). Traditional assessments sum up foregone output due to pollution-induced premature deaths (Cohen et al., 2017). This approach obscures costs associated with less acute health or cognitive effects (Zivin and Neidell, 2018). A body of evidence points out that bad air quality reduces supply and productivity of labor, even in occupations demanding mainly cognitive effort (Zivin and Neidell, 2012; Hanna and Oliva, 2015; Chang et al., 2016, 2019). These 'hidden' costs add up to economically important drops in output. Analyzing European regions, Dechezleprêtre et al. (2019) find that a $10 \%$ increase in air quality causes a $0.8 \%$ surge in GDP within the same year. These findings imply that cleaner air is responsible for up to $15 \%$ of Europe's GDP growth between 2000 and 2015 .

We study the effect of air pollution on aggregate inventive output. This effect does not show up in GDP because inventions typically take several years to realize economic benefits through product and process improvements (Scherer, 1965; Ravenscraft and Scherer, 1982). These lagged benefits may be large because innovation is a key driver of economic growth (Aghion and Howitt, 1990; Romer, 1990). Therefore, the costs of air pollution may be considerably understated when overlooking its effect on innovation.

We analyze a yearly panel of 1,288 European NUTS-3 regions between 2001 and 2012. We measure inventive output as the total number of patents filed in the year following a given level of exposure to air pollution. This one-year lag accounts for the fact that the process of drafting and filing a patent takes 6-12 months. Our measure of air pollution is the exposure to particulate matter with a diameter of 2.5 micrometers or less $\left(P M_{2.5}\right)$. These small particles enter the bloodstream through the lungs and affect the functioning of several organs (Underwood, 2017). $P M_{2.5}$ is one of the primary pollutants considered by the World Health Organization (WHO) and is commonly used as a measure of air pollution. 
Our identification strategy relies on two weather phenomena that provide plausibly exogenous variation in air pollution. ${ }^{1}$ Our first instrument measures a region's exposure to 'thermal inversions' during a given year. These inversions are caused by idiosyncratic atmospheric conditions and 'trap' pollutants near the earth's surface by reversing the negative temperature-height relationship. Our second instrument measures the level of natural ventilation that disperses pollutants. It is a function of wind speed and the height of the 'planetary boundary layer'. This layer determines the volume over which turbulent air flows are able to diffuse pollutants. We include controls for wind speed, precipitation, temperature, humidity and air pressure to account for the possibility that weather conditions correlated to our instruments affect innovation, for instance, by their impact on traffic conditions or mood.

We find that a $0.17 \mu \mathrm{g} / \mathrm{m}^{2}$ decrease in $P M_{2.5}$ concentration - the average yearly reduction in Europe over the period studied - leads to $1.7 \%$ more patented innovations. This effect is driven almost exclusively by regions with above-median levels of air pollution, suggesting that up to certain levels of exposure, the effects on innovation are small or non-existent. Increased air quality has a similar impact on total innovation for regions with high and intermediate levels of urbanization. ${ }^{2}$ This finding suggests that the potential benefits of reducing air pollution extend beyond highly urbanized regions.

Our baseline results measure the effect of air pollution on innovative output for the average region. One concern with aggregating these region-level estimates to economy-wide costs is that they may result from reallocation of human capital rather than decreased productivity. Indeed, if inventors migrate in response to air pollution, inventive output

\footnotetext{
${ }^{1}$ Other papers that use weather conditions to instrument air pollution include Hanna and Oliva (2015); He et al. (2019); Dechezleprêtre et al. (2019).

${ }^{2}$ For regions with intermediate levels of air pollution, the marginal effect is larger, but because of a lower patent intensity, the overall effect is similar.
} 
lost in one region may be partially recovered in another one. We rule out this mechanism using address information ${ }^{3}$ across inventors' subsequent patent applications to identify migration between regions. ${ }^{4}$ We find no statistically or economically significant effect of air pollution on inventor in- or out-migration. ${ }^{5}$

In a final set of analyses, we substantiate our claim that the effect on innovation is indeed not captured by prior assessments. First, we find suggestive evidence that changes in $R \& D$ expenditures do not drive our results. Because $R \& D$ spending is part of a region's GDP, the damages to innovation through this channel would be partially accounted for by the estimates of Dechezleprêtre et al. (2019). While our data do not allow for a direct test, we find suggestive evidence to rule out the R\&D spending mechanism. We show that our results hold when looking at scientific instead of inventive output. Because the funding of science is unlikely to react to changes in air pollution within a year, we would expect a considerably smaller effect on scientific output if $R \& D$ expenditures would drive our main result. In addition, the quality of patents in response to air pollution is not affected. When R\&D spending would be materially affected, average invention quality should go up because budget-constrained firms would arguably shut down less promising projects first. Second, we find that mortality in general does not react to air pollution in our set-up. If this would be the case, the traditional cost estimates that calculate costs due to productive life-years lost due to pollution-induced mortality would partly account for our main result.

While we do not disentangle the exact mechanisms behind our results, we see two remaining candidates. First, the supply of innovative labor may decrease due to absenteeism or a reduction in hours worked. This is consistent with prior work showing that labor supply decreases in response to air pollution (Hanna and Oliva, 2015; Aragón et al., 2017; Chang et al., 2019). Second, air pollution may reduce inventor productivity

\footnotetext{
${ }^{3}$ Inventors are obliged to disclose their address when applying for a patent

${ }^{4}$ We make use of the inventor name disambiguation algorithm developed in Morrison et al. (2017) to circumvent the fact that inventors are not assigned a persistent identifier in the patent database.

${ }^{5}$ Prior work has established that location choices depend on air quality (Khanna et al., 2021; Heblich et al., 2021). However, the variation to air pollution induced by our instrument is likely too small to invoke a migration response.
} 
conditional on hours worked by harming cognitive function. This is consistent with a recent stream of literature that finds considerable effects of air pollution on cognitively demanding tasks (Stafford, 2015; Ebenstein et al., 2016; Archsmith et al., 2018; Künn et al., 2019; Nauze et al., 2021).

A back-of-the-envelope calculation using existing estimates of the value of inventions shows that the magnitude of the effect of air pollution on inventive output is large. The average private value of a representative sample of European patents is estimated at 3 mln. euros (Gambardella et al., 2008). In addition, innovations induce spillovers valued at twice the amount of their private returns (Bloom et al., 2013). Summing up these two sources of value suggests that the yearly realized reduction in air pollution in Europe has created a benefit of 21.3 bln. euros annually. As a consequence, our results suggest that the GDP-effect from Dechezleprêtre et al. (2019) needs to be revised upwards by at least 10\%. This is a lower-bound estimate for two reasons. First, the private returns estimated by inventors are about 5 times lower as compared to stock-market-based estimates from Kogan et al. (2017). Second, estimates in Bloom et al. (2013) take into account knowledge spillovers and product market rivalry to estimate social returns. This assessment excludes further societal benefits, which are hard to estimate but considered to be large (Jones and Summers, 2020).

The remainder of the paper proceeds as follows. Section 2 outlines the empirical strategy we employ to estimate the causal effect of air pollution on inventive output. Section 3 describes the data and measures used. Section 4 discusses the results of our preferred specification, documents several robustness checks, and explores heterogeneity across regions. Section 5 provides the evidence to rule out mechanisms related to inventor mobility, R\&D expenditures and mortality. Section 6 concludes. 


\section{Empirical strategy}

\subsection{Measures for air pollution and innovation}

Air pollution. We proxy exposure to air pollution using the level of $P M_{2.5}$ concentration $^{6}$ in a region. $P M_{2.5}$ is one of the priority pollutants under EU air quality regulations (European Parliament and Council of the European Union, 2008) and the National Ambient Air Quality Standards (NAAQS) in the United States (US EPA (US Environmental Protection Agency), 1997). Other common air pollutants such as nitrogen oxides and ozone are not recorded at a scale suitable for our analyses. Therefore, we cannot disentangle the effects of $P M_{2.5}$ from those of other pollutants insofar these are correlated. We view this as only a small caveat for three reasons. First, $P M_{2.5}$ is considered the most harmful pollutant to cognitive function and physical health and is seen as a reference indicator to track air pollution globally (Power et al., 2016; WHO, 2016). Therefore, it is unlikely that co-pollutants importantly confound the effect. Second, the correlation between $P M_{2.5}$ and other pollutants stems from the fact that they result from similar industrial activities involving combustion. As such, regulations targeting $P M_{2.5}$ reduce co-pollutants as well, indicating that the main implications of this study hold even if co-pollutants partially drive the effects. Third, being the most widely used measure, the use of $P M_{2.5}$ ensures comparability of our results with the largest possible number of prior studies.

Innovation. To proxy innovation output, we use the yearly number of patent applications filed for in a region. The patent system is designed as a 'deal' between the public and an innovator. In order to receive the exclusive right to use and sell the patented invention in a jurisdiction, the innovator is required to disclose detailed information about the invention to the public. This publication requirement has the objective to allow others to build further upon the knowledge disclosed in the patent, increasing the efficiency of knowledge generation. As a side effect, patent data provide a window on innovative output for studies of technological change, innovation and economic growth (Griliches,

\footnotetext{
${ }^{6} P M_{2.5}$ refers to suspended particulates smaller than $2.5 \mu \mathrm{m}$ in aerodynamic diameter.
} 
1990; Schmookler, 1966; Trajtenberg, 1990). In this study, we benefit from the fact that most jurisdictions require inventors to state their address when applying for a patent. Recent efforts to geo-locate these addresses allow us to assign patented inventions to NUTS-3 regions (the European equivalent to US counties).

Three issues regarding patent data deserve attention here. First, not all inventions are patented because, when it is easy to maintain secrecy, the innovator has an incentive to minimize knowledge leaks to competitors. Hence, patents represent a lower bound of innovation output. Second, patents do not provide information on inventive inputs. As such, we cannot disentangle labor supply (hours worked) from labor productivity (output conditional on hours worked). Third, we observe the timing of a patent filing, rather than when inventive activity occurred. We assume the bulk of inventive activity takes place during the calendar year preceding the patent filing. This lag is included to account for the fact that preparing and filing for a patent takes an estimated 6-12 months (Scherer, $1965) .^{7}$

\subsection{Instrumental variables}

Estimating the causal effect of air pollution on innovation is challenging because of several unobserved confounders. For instance, technological opportunity or profits could affect innovation while co-varying with economic activity, the main driver of pollution. Omitting them would lead us to underestimate the damage done by air pollution. Reverse causality problems could further attenuate this bias. Albeit less obvious, air pollution might negatively affect innovation while inventive activity itself could contribute to air pollution. Such a mechanism would further understate the costs of low air quality. We address these endogeneity problems using two meteorological sources of variation.

\footnotetext{
${ }^{7}$ We conducted an interview with a patent attorney to confirm this is a reasonable assumption. Also note that inventors are unlikely to postpone patent filing until much after the conclusion of the inventive activity. Indeed, inventors have a strong interest to file for a patent close to the invention date (Griliches, 1990). The requirements for an invention to qualify for a patent are novelty and non-obviousness. Any evidence that the invention was already known before and, thus, violating the novelty criterion is called prior art. Consequently, the closer the filing and invention date, the smaller the pool of potential prior art.
} 
Thermal inversions. Typically, temperature decreases with height in the lower part of the atmosphere (the troposphere). Less dense warm air moves upwards and dilutes pollutants vertically. Thermal inversions reverse this monotonic relationship. Warmer air at higher altitudes hamper vertical dilution and traps pollutants at ground level (see Figure 1) (Vallero, 2014). Following Dechezleprêtre et al. (2019) and Arceo et al. (2016), we exploit this phenomenon to construct an instrumental variable for air pollution by calculating the annual share of days with a thermal inversion in a region.

Ventilation capability. Our second instrument measures variation in natural ventilation of pollutants. The atmospheric literature measures the dispersion speed of pollutants using the ventilation coefficient (VC), i.e. the product of wind speed and boundary layer height (Holzworth, 1967, 1972). Wind speed determines horizontal dispersion of pollutants whereas boundary layer ${ }^{8}$ height determines the volume of air among which pollutants can disperse in the atmosphere. On days with a high ventilation coefficient, concentration of air pollutants is low because natural ventilation allows them to dilute quickly. Figure 2 provides a schematic representation of the ventilation coefficient. To construct our instrument, we first calculate the daily ventilation coefficient for each region. We then obtain the annual average length of spells of consecutive days with a low ventilation coefficient - which we call Ventilation Capability. The logic behind this approach is that spells of consecutive days with limited natural ventilation - rather than the average number of days - drive pollution concentrations. ${ }^{9}$

\footnotetext{
${ }^{8}$ The planetary boundary layer is the lower part of the troposphere that experiences most turbulent air flow (which is crucial for diluting pollution) because of its interaction with the surface of the earth. The height of this layer varies based on the earth's topography as well as meteorological conditions.

${ }^{9}$ To make this clear, consider two regions that are identical in terms of pollution generation, but face a different daily ventilation coefficient distribution. In one region, low ventilation coefficient days are followed by high ventilation coefficient days, while in the other region low ventilation coefficient days are concentrated in time. Any one day's pollution in the former region will affect humans living there for one day only before ventilation disperses it, while in the latter region one day's pollution will affect humans for multiple days in a row before being dispersed. As a result, the average air pollution in the latter region will be higher.
} 
Relevance assumption. Several atmospheric studies have documented a positive correlation between thermal inversions and air pollution (Gramsch et al., 2014; Xu et al., 2017). Similarly, the negative correlation between the ventilation coefficient and air pollution is well-established (Hou et al., 2018; Genc et al., 2010). Our descriptive findings (section 3.1) and first-stage results (section 4) show a strong correlation between both instrumental variables and air pollution, justifying the relevance assumption of our IV approach.

Exclusion restriction. Our instruments plausibly affect inventive output only through their effect on air pollution. They provide a source of exogenous variation because they result from large-scale atmospheric dynamics unrelated to human activity (Stull, 1988; Garratt, 1994). As argued in Dechezleprêtre et al. (2019), the relevant literature provides no evidence of pollution causing thermal inversions rather than vice versa. None of the meteorological literature on the ventilation coefficient claims it is any way human-induced. In addition, our instruments pass the common test for over-identifying restrictions (Hansen, 1982). One potential concern might be that our instruments correlate to other weather conditions that affect innovation through for instance traffic conditions or the mood of inventors. To mitigate this concern, we control for average wind speed, precipitation, temperature, humidity and air pressure. Being exogenous themselves, they account for any correlation between innovation and weather conditions. ${ }^{10}$

\subsection{Econometric Model}

Our first-stage regression estimates the impact of our two instruments on $P M_{2.5}$. Unlike actual $P M_{2.5}$ concentration, predicted $P M_{2.5}$ concentration levels are exogenous to innovation and can be used to estimate the causal impact of air pollution on innovation. The first-stage regression has following specification:

$$
P_{i t}=\alpha_{1} T I_{i t}+\alpha_{2} V C_{i t}+\alpha_{3} P_{o p}+\alpha_{4} X_{i t}+\omega_{c t}+\eta_{i}+\nu_{i t}
$$

\footnotetext{
${ }^{10}$ In fact, our results show that these weather conditions have a marginal, if any, effect on innovation output in our specification.
} 
$P_{i t}$ is the average population-weighted $P M_{2.5}$ concentration for region $i$ in year $t$. Following Dechezleprêtre et al. (2019), we weight $P M_{2.5}$ concentration for population density in order to measure individuals' exposure to air pollution, rather than air pollution itself. The first instrumental variable $T I_{i t}$ measures the annual share of days with thermal inversions in region $i$. The second instrumental variable $V C_{i t}$ measures the average length of consecutive days with a low ventilation coefficient in year $t$ for region $i$. We define a low ventilation coefficient as any daily average ventilation coefficient that is equal or below the $20 t h$ percentile of the distribution of daily average ventilation coefficients in region $i$. Pop $_{i t}$ is the total population for region $i$ in year $t{ }^{11} X_{i t}$ is a vector of weather covariates controlling for weather conditions on the ground in region $i$. It includes annual means for wind speed, temperature, surface pressure, relative humidity and total precipitation. This vector also includes the second-degree-polynomials of all weather variables to account for a more flexible functional form. $\omega_{c t}$ are country-year fixed effects and $\eta_{i}$ are regional fixed effects. Last, $\nu_{i t}$ is the error term (which we allow to be clustered at regional level) that captures all unobserved determinants of pollution.

The second-stage regression estimates the causal impact of $P M_{2.5}$ on inventive output and has following specification:

$$
Y_{i t}=\beta_{1} \widehat{P_{i t}}+\beta_{2} P_{o p} i t+\beta_{3} X_{i t}+\lambda_{c t}+\alpha_{i}+\varepsilon_{i t}
$$

$Y_{i t}$ represents output from inventive activity in year $t$ and is measured by the number of patent filings in the following year by inventors living in region $i$. $\widehat{P_{i t}}$ is the predicted $P M_{2.5}$ concentration from the first-stage. $\lambda_{c t}$ are country-year fixed effects that account for country-specific time-varying effects, for instance exposure to macroeconomic shocks or changes in national regulations. $\alpha_{i}$ are region-fixed effects that eliminate any time-

\footnotetext{
${ }^{11}$ We do not control for GDP because it directly affected by air pollution and may correlate to innovation. Therefore, GDP would introduce endogenous selection bias (Pearl, 2009).
} 
invariant effects on pollution and innovation. As such, our specification relies on withinregion year-to-year variation in pollution caused by the instruments. Last, $\nu_{i t}$ is the error term for the second stage (allowed to be clustered at regional level) and captures all unobserved determinants of innovation output.

\section{Data \& Measures}

Patents. To measure inventive output, we rely on patent data from the EPO PATSTAT database (Spring 2018 edition). We link patent filings to NUTS-3 regions in Europe using the geolocation effort described in de Rassenfosse et al. (2019). This method retrieves geographic coordinates from inventor addresses using on-line geolocation services. Because one invention is typically described in various patent documents at different times ${ }^{12}$, one inventor may be linked to multiple addresses. The geolocation method assigns geographical coordinates to the inventor address that was disclosed at the earliest observed date. When tracking inventor migration, we use data that allows to trace inventor addresses over time (Morrison et al., 2017). This method assigns a stable inventor identifier across multiple patent documents for patents filed at the European Patent Office (EPO), the World Intellectual Property Office (WIPO), and the US Patent and Trademark Office (USPTO). This dataset is appropriate to identify inventor relocation for two reasons. First, it allows to track individual inventors across patent applications by employing a name disambiguation algorithm. Second, it geolocates addresses from each publication associated to the patented innovation, rather than the priority filing only, as is done in de Rassenfosse et al. (2019). These features allow us to more precisely detect inventor

\footnotetext{
${ }^{12}$ The patent application process typically takes several years. After filing, examiners produce an initial search report documenting the relevant prior art and assessing patent criteria such as novelty and inventive step. In response to this search report, applicants are often required to modify the patent patent application before it is granted. At each of these stages in the process, patent offices publish patent documents that we observe in the database. In addition, innovators seeking protection across different jurisdictions will file several patent applications at different patent offices. All the patent documents related to an invention are grouped into so-called patent families by the PATSTAT database.
} 
relocation events because there are more documents from which we can infer an inventor's address. We use the number of times a patent was cited to infer patent quality. This indicator is extracted from the PATSTAT database and counts the number of patented inventions that cite the focal invention. ${ }^{13}$

Scientific publications. To estimate the effect of air pollution on scientific output, we use data from the PubMed database maintained by the National Library of Medicine (NLM) at the National Institutes of Health (NIH). It contains a comprehensive account of scientific publications in biomedical and life sciences. To map publications to regions, we use geocodes from author affiliations listed on the publication (Torvik, 2015). Our measure counts the yearly number of first-author ${ }^{14}$ publications in a region. To ensure that we include true scientific output, we only include publications from organizations that Torvik (2015) classifies as 'educational', 'hospital', 'educational-hospital' and 'organization'.

Pollution. We use gridded data on the annual average ground-level fine particulate matter $\left(P M_{2.5}\right)$ concentrations from Hammer et al. (2020) and Van Donkelaar et al. (2019). These data contain estimated pollution concentrations at a fine spatial resolution of $0.01^{\circ} \times 0.01^{\circ}$ by combining Aerosol Optical Depth (AOD) retrievals from satellites with regional ground-level observations. We combine pollution data with gridded data on the population of Europe from CIESIN (Columbia University, 2018) to obtain the population-weighted $P M_{2.5}$ concentration. ${ }^{15}$

Meteorological information. We obtain atmospheric data from the MERRA-2 dataset (Gelaro et al., 2017) to determine the presence of thermal inversions. This data set contains daily mean temperature and relative humidity for 42 different pressure levels at respective heights. This information allows us to calculate the temperature-height relationship that defines thermal inversions. Following Dechezleprêtre et al. (2019), we

\footnotetext{
${ }^{13}$ It uses aforementioned patent family concept to identify an invention from the patent documents it is related to. This approach avoids double-counting of citation linkages between patent documents that represent the same invention.

${ }^{14}$ In the biomedical literature, ghost, gift or honor authorships are not an exception. Using first authors only mitigates this concern by picking up the main contributor to a project (Yang et al., 2017).

${ }^{15}$ Population estimates are available every 5 years starting in 2000 and ending in 2020 . We always use the closest population estimated to calculate annual weighted $P M_{2.5}$ concentration in year t.
} 
identify the occurrence of a thermal inversion when the temperature is higher at the second-to-lowest level of the atmosphere than at the lowest level. To circumvent the problem that the spatial resolution $\left(0.5^{\circ} \times 0.625^{\circ}\right)$ of these data is too coarse to cover smaller NUTS-3 regions, we interpolate these data to a finer resolution $\left(0.01^{\circ} \times 0.01^{\circ}\right)^{16}$. The thermal inversions instrument is calculated as the annual share of days with a thermal inversion for each region.

Further atmospheric and climate data for the period 2001-2018 come from the family of ERA5 datasets provided by the European Centre for Medium-Range Weather Forecasts. ${ }^{17}$ Specifically, we make use of the ERA5 data (Hersbach et al., 2020) and the ERA5-Land data (Muñoz-Sabater, 2019) to calculate the ventilation coefficient and additional weather control variables. We use ERA5 hourly data on the boundary layer height to calculate daily means for each NUTS-3 region. ${ }^{18}$ We calculate daily means for temperature, wind speed, surface pressure and precipitation using ERA-5-Land hourly data. ${ }^{19}$. Ventilation Capability (VC) is calculated as the annual average number of consecutive days in which the ventilation coefficient is equal or below the 20th percentile of the distribution of ventilation coefficients within a NUTS-3 region. ${ }^{20}$

Geographic indicators. We collect geographic indicators for NUTS-3 regions from Eurostat $^{21}$. We use yearly data on population ${ }^{22}$, regional classifications ${ }^{23}$ and mortality ${ }^{24}$.

\footnotetext{
${ }^{16}$ For temperature we use a simple bi-linear interpolation technique because temperature varies between geographic locations rather continuously. As relative humidity is spatially discontinuous, we apply nearest-neighbor interpolation technique.

${ }^{17}$ An overview of all ERA5 datasets can be found on https: //confluence.ecmwf.int/display/CKB/The + family + of + ERA $5+$ datasets.

${ }^{18}$ Again, we use bi-linear interpolation to increase spatial resolution from $0.25^{\circ} \times 0.25^{\circ}$ to $0.05^{\circ} \times 0.05^{\circ}$

${ }^{19}$ These data are provided at a spatial resolution of $0.1^{\circ} \times 0.1^{\circ}$, which is sufficient to cover smaller NUTS-3 regions.

${ }^{20}$ We calculate the ventilation coefficient as the product of daily mean wind speed and daily mean boundary layer height.

${ }^{21}$ Eurostat databasse are accessable on https://ec.europa.eu/eurostat/data/database.

${ }^{22}$ We use the "demo_r_pjanaggr3" dataset.

${ }^{23}$ We use the classification of metropolitan regions which can be found on https://ec.europa.eu/eurostat/web/rural-development/background.

${ }^{24}$ We use the "demo_r_deaths" dataset.
} 


\subsection{Descriptive findings}

We restrict the sample period to 2001-2012 to avoid truncation bias due to a drop-off in patent counts during recent years of the database. As a patent application only enters our data set at the time the first patent document is published, time series towards the end of the database show a negative trend. This does not necessarily reflect an actual drop in the number of patent application, but rather the lag by which patent applications are observed. To avoid truncation bias due the fact publication lags could correlate to unobserved determinants of innovation, we restrict our sample to the period 2001 until 2012, well before any truncation starts.

Figure 3 shows the annual average number of patent filings by inventors of a NUTS-3 region for the sample period. ${ }^{25}$ Western Germany, southern-UK, northern-France and the Nordic countries have highest patent output, while Eastern European countries and Spain show lower patenting activity. The spatial distribution maps well to measures of R\&D intensity and R\&D growth reported in the Research and Innovation Performance report published by the European Commission (2020), lending support to our measure of patent filings as an indicator for inventive output.

Figure 5 (blue line) documents a decreasing trend in $P M_{2.5}$ concentration over time. On average, $P M_{2.5}$ concentration falls by $0.17 \mu \mathrm{g} / \mathrm{m}^{3}$ each year. A similar trend appears for nearly all air pollutants in Europe (Koolen and Rothenberg, 2019), indicating a steady improvement of Europe's air quality. Nevertheless, $P M_{2.5}$ concentration varies across EU Member states. Figure 4 shows the annual average $P M_{2.5}$ concentration of NUTS-3 regions in the sample period. Eastern European regions, together with northern Italy, experience higher pollution levels than the rest of Europe. The spatial distribution in $P M_{2.5}$ concentration is in accordance to $P M_{2.5}$ measures from local stations published in the Air quality in Europe report by the European Environment Agency (2020). While informative to validate our measure, the region-fixed effects in our specification purge all cross-sectional variation in innovation and pollution.

\footnotetext{
${ }^{25}$ In case multiple regions are assigned to one patent because different inventors on the patent live in different regions, we assign the patents to both regions.
} 
Figure 5 shows the yearly variation in $P M_{2.5}$ concentration and the two instrumental variables, thermal inversion and ventilation capability. Trend lines of the instrumental variables show a remarkably strong correlation to $P M_{2.5}$ concentration, providing nonparametric evidence for the strength of our instruments.

\subsection{Summary statistics}

Our sample includes observations for 1288 NUTS-3 regions within 30 countries for the period $2001-2012 .{ }^{26}$ We trim our measure of $P M_{2.5}$ concentration at $1 \%$ at each side of the distribution to remove outliers indicating unrealistically high or low levels of pollution. ${ }^{27}$ We drop NUTS-3 regions with only a limited number of patent filings. ${ }^{28}$ We do this because we believe patent counts to be a poor indicator of inventive activity for regions with zero or only a handful of patents per year. Therefore, including these regions would plausibly introduce measurement error. Figure 6 shows NUTS-3 regions that are dropped from the baseline analyses, most of which are in the Balkan area. Our baseline result is robust to keeping these regions in the sample.

Table 1 shows summary statistics for the sample data. On average, we observe 109 patent filings per year within a NUTS-3 region. This distribution is left-skewed with a median of only 41 filed patents. Hence, we use the natural logarithm of the number of patents (plus one) in subsequent analyses. The annual average population-weighted $P M_{2.5}$ concentration per NUTS-3 region amounts to $13.62 \mu \mathrm{g} / \mathrm{m}^{3}$.

\footnotetext{
${ }^{26}$ The longest period spanned by our data set is 2001-2018, but we drop years after 2012 due to truncation in the data on patent filings (section 3.1).

${ }^{27}$ No outliers were detected for the other variables in our models.

${ }^{28}$ The baseline specification drops regions below the 5th percentile in terms of total number of patent filings. Keeping these regions in only slightly decreases the coefficients of interest. Increasing the threshold to the 10th or 15th percentile increases the coefficients, possibly due the fact that innovation intensity correlates to pollution levels.
} 


\section{Main Results}

\subsection{Baseline}

Table 2 presents the baseline results. The instrumental variables strongly predict air pollution. In line with our expectations, both instruments cause an increase in $P M_{2.5}$ concentration. Reassuringly, including both instruments together barely changes their coefficients. Table 3 shows summary statistics of the predicted $P M_{2.5}$ concentrations resulting from our 1st-stage regressions. It examines variation in predicted $P M_{2.5}$ values induced only by the instruments ${ }^{29}$. The last row shows that the standard deviation of fitted $P M_{2.5}$ concentrations is $0.39 \mu \mathrm{g} / \mathrm{m}^{3}$ in our preferred specification (third regression in table 2). It ranges between $12.83 \mu \mathrm{g} / \mathrm{m}^{3}$ and $15.52 \mu \mathrm{g} / \mathrm{m}^{3}$. Figure 7 plots the standard deviation of these fitted $P M_{2.5}$ concentrations across NUTS-3 regions. Nearly all NUTS-3 regions show similarly strong instrument-induced variation.

The first column of Table 2 shows OLS estimates of a model identical to equation 2 where we replace fitted pollution levels to observed ones. The next four columns show the second- and first-stage results by instrumenting $P M_{2.5}$ concentration with thermal inversions or ventilation capability respectively. Finally, the last two columns show the secondand first-stage results by instrumenting $P M_{2.5}$ concentration with both instrumental variables. In line with expectations, OLS estimates are smaller than estimates obtained with the IV regressions, suggesting that omitted variables and reverse causality lead to underestimation of the harmful effects of air pollution (section 2). Both instrumental variables lead to similar results (second and fourth column). In our preferred specification (second to last column), an increase in the $P M_{2.5}$ concentration with $1 \mu \mathrm{g} / \mathrm{m}^{2}$ causes a reduction in the number of patent filings per NUTS-3 region of $10 \%$. This implies an elasticity at the sample mean of 1.36. Our reference increase corresponding to the year-to-year average decrease in pollution in Europe of $0.17 \mu \mathrm{g} / \mathrm{m}^{2}$ (see section 3.1) lies within the variation induced by our instruments mentioned above, and has caused a $1.7 \%$ change in inventive output.

\footnotetext{
${ }^{29}$ We fix control variables at their mean
} 
The common IV regression test statistics confirm the validity of the assumptions underlying our analyses. First, the Kleibergen-Paap F statistics are high for all IV regressions and above critical values for weak instruments formulated in Stock and Yogo (2002). ${ }^{30}$ Second, with a p-value of above $5 \%$, the Hansen test supports the exogeneity assumption of our instruments.

\subsection{Count Model}

In a first robustness check, we apply a count data model rather than a linear model to our data. As the number of patent applications only has non-negative values and its distribution has a relatively large mass on low values, count models could improve the specification of the error term distribution. Count data models with multiple fixed effects that also correct for endogenous regressors have been only recently established (Lin and Wooldridge, 2019). Specifically, we use a poisson fixed-effects model which is robust for under- and overdispersion (Wooldridge, 1999). Hence, we assume that the annual number of patent applications per NUTS-3 region follows a poisson distribution. Furthermore, we use a control function approach to account for endogeneity of the $P M_{2.5}$ concentration in the non-linear fixed-effects model. ${ }^{31}$ The control function approach predicts residuals from the first-stage regression. Next, predicted residuals together with endogenous $P M_{2.5}$ levels can be consistently estimated in the poisson-fixed-effects regression. This follows the idea that predicted residuals from the first-stage regression will control for endogeneity. ${ }^{32}$ The first-stage regression used to predict residuals are identical to equation 1. Resulting poisson fixed-effects regression can be written as:

$$
Y_{i t}=\xi_{1} P_{i t}+\xi_{2} \widehat{v_{i t}}+\xi_{3} P_{o p} p_{i t}+\xi_{4} X_{i t}+\lambda_{c t}+\alpha_{i}+\varepsilon_{i t}
$$

\footnotetext{
${ }^{30} \mathrm{~F}$-statistics for the three IV-regressions are all above the $10 \%$ Stock and Yogo (2002) critical values.

${ }^{31}$ This is important since the regular two-stage least squares estimator might not be consistent in combination with a non-linear second-stage regression.

${ }^{32} \mathrm{~A}$ simple endogenous model can be written as $y_{1}=\beta_{1} y_{2}+\beta_{3} z_{1}+u_{1}$ where $y_{2}$ is the endogenous explanatory variable and $z_{1}$ a vector of exogenous regressors. The linear projection of $y_{2}$ on the exogenous regessors is $y_{2}=\alpha_{1} z_{1}+v_{2}$ and can be the first-stage in a 2SLS approach. Endogeneity of $y_{2}$ arises only if $u_{1}$ is correlated with $v_{2}$ which can be formalized as $u_{1}=\rho_{1} v_{2}+e_{1}$. Hence, predicting residuals from first stage $v_{2}=y_{2}-\alpha_{1} z_{2}$ and plugging them in the first stage $y_{1}=\beta_{3} z_{1}+\beta_{1} y_{2}+\rho_{1} \hat{v}_{2}+$ error controls for endogeneity.
} 
$P_{i t}$ is the actual $P M_{2.5}$ concentration in year $t$ in NUTS-3 region $i$. $\widehat{v_{i t}}$ are predicted residuals obtained from the first-stage regression and account for the endogeneity of $P_{i t}$. Other specifications are identical to equation 2 with the important difference that they allow the outcome measure to follow a poisson distribution.

Table 14 shows the results for the poisson fixed-effects regressions for a sample including all NUTS-3 regions. The first column shows results without control function approach. The second column shows results for the control function approach by simply adding the first-stage residuals (equation 1) to the poisson fixed-effects regression. We use 500 bootstrap replications to obtain the standard errors, where we re-sample NUTS3 regions. The coefficient of the $P M_{2.5}$ variable is -0.07 , indicating that an increase in the $P M_{2.5}$ concentration by $1 \mu \mathrm{g} / \mathrm{m}^{2}$ causes the number of patent filings to drop by $7 \%$. This effect is only slightly smaller than that obtained with the linear regression model. This result leads us to conclude that our results are robust for using a count model specification.

\subsection{Accounting for spatial and serial correlation}

Tobler (1970) formulates the first law of geography as: "Everything is related to everything else, but near things are more related than distant things". Applied to our setting this means that observations for one NUTS-3 region are possibly statistically related to observations from neighboring NUTS-3 regions, raising concerns about spatial autocorrelation. In addition, pollution, weather, and economic data are likely to be correlated over time. To address these concerns, we estimate models that allow standard errors to be spatially and serially correlated (Conley, 1999, 2010). Conley's procedure requires a cutoff for spatial and serial correlation. We estimate two models with different assumptions on the cutoff points allowing for more robust inference. 
Table 15 column 1 shows baseline results with SEs clustered at NUTS-3 level. Column 2 shows results with Conley's SEs assuming a spatial correlation range of 500 kilometers ${ }^{33}$ and a serial correlation range of 5 years. Similarly, column 2 shows results with Conley's SE assuming a spatial correlation range of 1000 kilometers and a serial correlation range of 10 years. Standard errors are slightly larger than baseline results when accounting for spatial and serial correlation but results remain significant when accounting for these different degrees of spatial and serial correlation.

\subsection{Further robustness checks}

We conduct several robustness tests to further examine the validity of our results. First, we alter the threshold for the definition of a low ventilation coefficient used to calculate the ventilation capability. Specifically, we define a low ventilation coefficient as any daily average ventilation coefficient that is equal or below the 10th, 15th, 20th and 25th percentile of the distribution of daily average ventilation coefficients within a NUTS-3 region. Table 16 shows results for the different ventilation capability measures. Overall, results are robust for altering the threshold for a low ventilation coefficient.

Second, we decrease and increase the threshold for excluding NUTS-3 regions with a low number of patent filings. Specifically, we estimate results without dropping any NUTS-3 region and dropping NUTS-3 regions equal or below the $5 t h, 10 t h$ and $15 t h$ percentile of the distribution for total number of patent filings. Results are robust for excluding NUTS-3 regions based on different thresholds of a low number of patent filings.

Third, we alter the sample period by excluding more recent years. Table 18 presents the results for the different sample periods. Results are robust for restricting the sample period up to the interval 2001-2008.

Fourth, we verify whether the main results are robust for excluding weather covariates. Table 20 shows results for the IV-regression on individual weather covariates. Overall, results are similar regardless of whether we include weather controls or not.

\footnotetext{
${ }^{33}$ Distances between NUTS-3 regions are determined by their center points.
} 
Fifth, table 19 presents results for regressing weather controls on the annual number of patent filings per NUTS-3 region. None of the weather control variables are significantly correlated with the number of patent filings. This suggests that weather does not impact inventive activity in our specification. Hence, the two weather phenomena which we use as instrumental variables are unlikely to impact the inventive activity other than through an increase in air pollution.

\subsection{Heterogeneity Regions}

The effects of additional air pollution are not necessarily the same for all regions. Understanding this potential heterogeneity across regions can help informing policy makers about where abatement efforts are best targeted. We first examine effect heterogeneity between high- and low-pollution NUTS-3 regions in order to examine non-linearity of the effects of air pollution - i.e. whether an increase in air pollution is more harmful to innovation where levels of air pollution are higher. To this end, we split our sample based on the median of region-level mean $P M_{2.5}$ concentration. The first, respectively last, two columns of Table 4 show the results of the second- and first-stage regressions for the sub-sample of regions with low, respectively, high levels of pollution. In less polluted regions, the coefficient of interest is small and insignificant. In contrast, negative effects of $P M_{2.5}$ concentration on the number of patent filings are large and highly significant for more polluted regions. For these regions, a $1 \mu \mathrm{g} / \mathrm{m}^{2}$ increase in the $P M_{2.5}$ concentration reduces the annual number of patent filings by $15 \%$. This finding suggests that harmful effects of pollution are concentrated in regions with relatively high levels of pollution.

Next, we investigate whether observed negative effects vary with the level of urbanization in a region. This is relevant to policy because effectiveness and costs of abatement programs may vary by level of urbanization. For instance, stimulating electrical driving is more likely to reduce pollution in urban areas, whereas limiting industry emissions might 
affect less urbanized areas. To understand how the effects of air pollution vary by level of urbanization, we split the sample into regions that are (1) predominantly rural, (2) intermediate and (3) predominantly urban - based on Eurostat's 'Rural Development' indicators $^{34}$.

Table 5 shows the results for this split sample. The three pairs of columns show the results of the second- and first-stage regressions for the sub-sample of predominantly rural, intermediate and predominantly urban NUTS-3 regions respectively. We do not find a significant effect of air pollution on innovation in predominantly rural areas. Interestingly, negative effects of $P M_{2.5}$ concentration on innovation are strongest for intermediate NUTS-3 regions with an elasticity of 2.36 at the mean $P M_{2.5}$ concentration. In the subsample of urban NUTS-3 regions the marginal effects of air pollution are in line with those in the overall sample, with an elasticity at the mean of 1.29. Importantly, urban and intermediate NUTS-3 regions show similar $P M_{2.5}$ levels (see Figure 8). Hence, the heterogeneity by pollution level is unlikely to explain the difference in these estimates. While the marginal effects starkly differ between urban and intermediate regions, this does not translate in important differences in absolute terms. Because of a higher innovation-intensity in urban regions, a $1 \%$ increase in the $P M_{2.5}$ level causes a reduction in the absolute number of patent filings similar to that of intermediate regions (4.8 for urban versus 4.1 for intermediate). A potential explanation for the observed difference in the elasticities might be differences in socio-demographic characteristics of the population in urban and intermediate areas. For instance, people living in urban areas are more highly educated, have higher incomes and are younger (Eurostat, 2017). These factors may affect how prone individuals are to the negative health effects, but also the quality of healthcare they receive. The fact that rural areas are barely affected might be due to lower levels of inventive activity (making it unlikely that patents pick up a lot of variation) or the lower overall levels of pollution in such regions.

\footnotetext{
${ }^{34}$ For more information, refer to https://ec.europa.eu/eurostat/web/rural-development/methodology.
} 


\section{Mechanisms}

In order to aggregate our region-level estimates to economy-wide costs that are not captured in previous estimates, we rule out a number of mechanisms that prohibit us from doing so. First, we examine the extent to which inventor mobility between regions can explain the results. This is important to reliably aggregate our estimates across regions. Indeed, if air pollution causes inventors to relocate to other regions, at least a portion of the human capital loss in one region is recovered by human capital gain in another one. If this mechanism is important, aggregating our estimates would lead to an overestimation of the economic costs induced by innovation.

Second, we investigate to which extent shocks to R\&D funding - a crucial input to the invention process - drive our results. While this mechanism does not preclude us from aggregating the effects across regions, it affects our claim that effects on inventive output are not captured in estimates of the effect of air pollution on short-term economic activity (Dechezleprêtre et al., 2019). Indeed, reductions in R\&D spending are likely to show up in measures of GDP. We do not observe R\&D expenditures for enough firms and regions to directly test this mechanism. However, we provide two pieces of evidence that suggest this mechanism does not explain our results. First, we examine the effect of air pollution on scientific output as measured by PubMed articles produced in a region. We view this as an adequate test because funding cycles in science are too long to immediately respond to air pollution. As such, finding that the effects on science are similar suggests that shocks to funding of R\&D are unlikely to explain a large portion of our effect. Second, we study the effect of air pollution on quality-weighted patent counts. If shocks to $R \& D$ funding are important in explaining our effect, we would expect that the average quality of inventions increases in response to variation in air pollution. Indeed, if air pollution affects $R \& D$ budgets (for instance, because air pollution may increase the expectation of costly regulation), this should reflect either in less $R \& D$ projects being started up or in existing $R \& D$ projects to be discontinued. Given that a reduction in new projects 
is not likely to show up in our results because the duration of inventive process, $R \& D$ budgets should mainly affect ongoing projects in our setting. If managers face budget constraints, it is likely that they discontinue less promising projects first. This would lead to an increase in average quality of the observed patented inventions.

Finally, we examine effects of air pollution on total mortality in our sample. Such increases in mortality would be picked up by previous estimates of the economic costs of air pollution as assessed by losses in productive life years (Landrigan et al., 2018). Finding that these losses are minimal in our specification, reassures us that the effects we find on inventive output are not captured in the mortality-based assessments.

\section{$5.1 \quad$ Inventor Mobility}

To identify relocation events and their timing, we chronologically order all inventors' addresses stated on their patents and mark switches between NUTS-3 regions. The relocation year of an inventor can be easily determined when such a switch happens within the same year or within two consecutive years. In this case we assume the relocation year corresponds to the year preceding the filing date of the latest patent stating the inventor's new address. ${ }^{35}$ When a switch co-occurs with a gap in time of multiple years, we use the median as relocation year. ${ }^{36}$ To exclude unreasonable movement patterns, we conduct the data-cleaning process proposed by Zacchia (2018) (see appendix F). Using these relocation events, we construct our measure of inventor relocation by counting the yearly number of inventor movements out of and into NUTS-3 regions for the sample period 2001-2012. To verify whether the decisions made in terms of selecting the relocation event year drive the results, we re-estimate our regressions using a sample with only relocation events that can be precisely determined. To account for the fact that relocation of more prolific inventors have a relatively large impact on a region's innovation output, we construct an additional measure in which we weight each relocation event by the number of patents respective inventors filed within five years before the relocation year.

\footnotetext{
${ }^{35}$ We take the preceding year to account for the 6-12 months lag between invention and patent application.

${ }^{36}$ Decimal numbers are rounded up assuming the relocation year is closer to the patent filed under the new address.
} 
It is important to mention that we are only able to observe migration of inventors that file patents before and after a relocation event. Migration before the first filed patent and after the last patent filing as well as multiple moves between two filings cannot be traced. As such, we have data for a sub-sample of relocating inventors. This raises the concern of selection bias because more prolific inventors may be more likely to be (able to afford) moving in response to pollution. While we cannot fully address this issue, the potential bias induced would be conservative because it would lead us to overestimate the number of moves in response to air pollution.

Overall 1,295,300 inventors who filed patents between 1944 and 2013 state addresses in NUTS-3 regions. Only 5.38\% of those inventors file patents in two different regions, suggesting that relocation is a rare event. Figure 9 shows relocation events of inventors between NUTS-3 regions for the sample period 2001-2012. Similarly, figure 10 shows relocation events of inventors between NUTS-3 regions and regions outside Europe. Unsurprisingly, most relocation events occur for regions with a high number of patent filings and R\&D investments (section 3.1) that are plausibly attractive to inventors.

We apply the regression model described in section 2.3 to estimate the impact of air pollution on the annual number of inventor relocations. Table 7 shows the results for out-migrating inventors. The first column shows results for the OLS estimation by simply regressing the total number of moves away from a region by inventors on $P M_{2.5}$ concentration without using instrumental variables. The second and third columns show the second- and first-stage results by instrumenting $P M_{2.5}$ with thermal inversion and ventilation capability. The fourth column shows OLS results for the patent-weighted measure of the number of in-migrating inventors. The last two columns show results for the same outcome variable when instrumenting for $P M_{2.5}$ concentration. OLS estimates are negative and significant indicating that increased $P M_{2.5}$ concentration reduces the likelihood of inventors migrating out of NUTS-3 regions. However, these results are likely to be driven by unobserved factors driving both pollution and migration, i.e. more innovative regions attract more inventors but are also more polluted. The IV regressions do not show statistically or economically significant results. To verify that the estimated 
coefficients cannot explain our baseline results, consider the upper bound of the $95 \%$ confidence interval around the coefficient -0.12 . Taking this as the true effect would imply that inventor migration in response to a $1 \mu \mathrm{g} / \mathrm{m}^{2}$ increase in $P M_{2.5}$ would increase with $12 \%$. Seeing that the baseline migration rate is about 2 inventors per year, this implies an outflow of inventors with about one fifth of an inventor. With about 0.8 patents per year per migrating inventor, this results in a reduction of 0.16 patents due to migration. The same increase in air pollution reduces the average number of patents in a region by about 11. As such, it becomes clear that, even for this very conservative calculation, migration could only marginally account for our baseline result. Furthermore, table 8 presents the same regressions for the restricted sample of relocation events where the relocation year is well defined. Again, IV estimates show small but insignificant coefficients. In conclusion, we do not find evidence that air pollution causes inventors to migrate. Table 9 shows the results for in-migrating inventors and has the same structure as the table for out-migrating inventors. Again, IV results for the total number and the weighted number of in-migrating inventors show small and insignificant coefficients. Again, results are robust to the restricted sample of relocation events where relocation year is well defined.

Taken together, we do not find evidence that negative effects of air pollution on innovation pick up inventor migration patterns between regions. These patterns are consistent with the idea that variation in air pollution induced by atmospheric conditions are too idiosyncratic and small to cause inventors to move into or out of a region because of them. In addition, it might be the case that air pollution affects migration of inventors, but rather within the narrow scope of a NUTS-3 region. Especially since migration costs increase with distance and inventors might have a strong interest to preserve local ties. 


\section{$5.2 \quad \mathrm{R} \& \mathrm{D}$ expenditures}

Scientific output. Table 11 shows the results of estimating the effect of $P M_{2.5}$ concentration on the annual number of published journal articles listed in PubMed. In line with the baseline result, the OLS estimate (column 1) is smaller than the estimate obtained by the IV regression. Coefficients from the IV regressions are statistically significant and imply that an increase in the $P M_{2.5}$ concentration with $1 \mu \mathrm{g} / \mathrm{m}^{2}$ causes a reduction in the number of published journal articles per NUTS-3 region of 9\%. This negative effect is very similar to negative effects of $P M_{2.5}$ concentration on the number of patent applications. Hence, air pollution affects scientific output about as strongly as inventive output.

Patent quality. To investigate whether air pollution affects the quality of observed inventions, we re-estimate our baseline specification after weighting patent counts for the total number of forward citations patents receive, a common proxy for the quality or technological importance of patents (Trajtenberg, 1990; Hall et al., 2001). We use two different measures for the number of forward citations. First, we count the number of forward citations patents received within a 5-year window. Second, we normalize the total number of forward citations by the average number of citations patents receive with the same filing year and technical field. For both measures we aggregate the number of forward citations for all patents filed within a NUTS-3 region. The first two columns of table 12 show the second- and first-stage regression results for the 5-year window forward citations measure. The last two columns show the results when using the normalized forward citations measure. Weighting for patent quality makes the negative effect of air pollution slightly stronger, but the coefficient is within the error of margin of our baseline specification. An increase in the $P M_{2.5}$ concentration by $1 \mu \mathrm{g} / \mathrm{m}^{2}$ causes patent counts normalized the number of forward citations to drop by 13\%, as compared to our baseline estimate of $10 \%$ (see section 4). Unreported regressions that use the average number of forward citations as an outcome measures show no statistically significant effect of air pollution. In sum, we find no clear evidence that the quality of inventive projects increases upon increased pollution exposure. 


\subsection{Mortality}

Last, we investigate whether the reduction in inventive output can be explained by an increase in mortality induced by air pollution. For this purpose, we apply the regression model described in section 2.3 and estimate immediate effects of air pollution on the annual number of deaths and annual death rate per NUTS-3 region. As we do not have reliable estimates of the number of inventor deaths, we conduct this analysis using total deaths per NUTS-3 region obtained from Eurostat. Prior research shows that inventors have high incomes, higher education and high-income parental backgrounds (Bell et al., 2019; Aghion et al., 2017). These socioeconomic factors are negatively correlated with mortality (Torssander and Erikson, 2009). As such, the death rate of the entire population is likely to be higher than the death rate of inventors. Therefore, using the total death rate is likely to overstate the importance of mortality in reducing innovation labor supply.

Table 13 presents results for the impact of $P M_{2.5}$ concentration on the natural logarithm of total number of deaths per NUTS-3 region. OLS estimates show negative and significant coefficients indicating positive effects of air pollution on mortality. However, these estimates are likely to be the results of unobserved factors driving both pollution and mortality, i.e. more innovative regions have higher economic activity and wealth, which likely reduce mortality. Instead, both IV regressions for the total number of deaths and the death rate show small and insignificant coefficients. We do not find evidence that baseline results on the reduction in innovation caused by pollution can be explained by increased mortality. Plausibly, the variation in air pollution induced by the instrumental variables is too small to considerably increase mortality. 


\section{Discussion}

Recent estimates of the effect of air pollution on economic activity suggest that pollution abatement can considerably contribute to growth. This study underscores that reducing air pollution could be even more beneficial than implied by these estimates because it may positively affect innovation. To examine the importance of this channel, we estimate the causal effect of air pollution on innovation using two weather phenomena as sources of exogenous variation.

We find a large negative effect of air pollution on innovation. The estimates suggest that a decrease in pollution of $0.17 \mu \mathrm{g} / \mathrm{m}^{3}$ - the yearly average decrease in Europe on average leads to $1.7 \%$ more patented innovations. At the mean pollution level, this implies an elasticity of 1.36. We find no evidence for a concurrent decline in average patent quality, so we can interpret our coefficients as effects on total innovative output. We also find that the negative effect of air pollution is concentrated in regions that are more polluted, suggesting that there is a non-linear relationship between pollution levels and innovation. In NUTS-3 regions above and below the median pollution level, respectively, the elasticities are 2.51 and 0.58 . The elasticity for predominantly urban areas is 1.29 and that of areas with intermediate levels of urbanization is 2.36 , while both types have similar pollution levels. In absolute levels, however, this difference amounts to about the same number of additional patents (4.8 for the average urban region, 4.1 for the average intermediate region) because urban areas have higher innovation intensity. In addition, we do not find evidence that inventor migration patterns may explain our results. As such, the negative effects of pollution on innovation in one region are unlikely to be made up for by more innovation in a different region through movement of human capital. Given the absence of such spillover effects, we believe that our results can be aggregated to the national and international level. Finally, we find suggestive evidence that shocks to R\&D budgets or increased mortality induced by air pollution are unlikely to explain the results. This suggests that the economic costs implied by reduced innovation output are not captured in previous assessments based on reduced human capital and short-term economic output (Landrigan et al., 2018; Dechezleprêtre et al., 2019). 
Our study contributes to previous work on the economic effects of air pollution by highlighting an additional channel through which pollution may harm economic activity. Endogenous growth theory has put innovation at the center stage in explaining economic progress (Romer, 1990; Aghion and Howitt, 1990). As innovation is unlikely to translate into firms' short-term productivity increases through improved processes or product quality within (maximum) one year, the observed effect on innovation is largely overlooked by previous assessments. As such, our findings highlight an additional channel through which pollution abatement creates economic value.

However, translating these findings into exact estimates of economic value is a nonobvious exercise. Next to increased profits by firms, innovations create several types of spillovers (Hall et al., 2010; Jones and Summers, 2020). On the one hand, estimating the contribution of innovation to firms' profits is hard because it is hard to disentangle how much each innovation contributes to lower costs or higher prices. On the other hand, taking into account a host of indirect effects of innovations on welfare is extremely challenging. That being said, the overarching consensus is that the value created by innovation is large, and that the portion of this value captured by the innovator is small (Nordhaus, 2004; Hall et al., 2005; Kogan et al., 2017; Jones and Summers, 2020). One approach to estimate the total economic value implied by our estimates is to combine inventors' estimates of the private value of their (European) patents (3 million euros on average) (Gambardella et al., 2008) with the ratio of spillovers to private returns as estimated in Bloom et al. (2013). This implies an average total value of about 9 million euros for each patented invention. Extrapolating this, leads to a back-of-the-envelop calculation of the expected effect of reducing pollution. In the average region, this would imply that decreasing pollution by $0.17 \mu \mathrm{g} / \mathrm{m}^{3}$ leads to a 16.5 million increase in economic value each year. Multiplying this by the number of regions leads to an estimated yearly value of 21.3 billion euros. Relative to the yearly GDP in Europe, this is about $0.014 \%$, which is $10 \%$ of the estimates in Dechezleprêtre et al. (2019). 
In addition to adding to the evidence on the costs of air pollution, our findings could help increasing efficiency of abatement policies. For instance, if a country's innovation is clustered in a region with a certain polluting industrial sector, abatement programs targeting this sector may be much more effective than targeting other, equally polluting sectors in less innovation-intensive areas. The heterogeneity in effects uncovered also informs policy makers. Particularly, our finding that the lion's share of the effect comes from highly polluted areas, suggests that targeting low-pollution areas may not be cost-effective (unless the cost of abatement programs across regions vastly differ). This is especially true seeing that highly polluted areas are also areas with high innovation intensity (they have 3.28 times more patents). Similarly, the heterogeneity by level of urbanization can also inform policy makers by highlighting that both highly urban and intermediate regions are important targets for abatement policies. Indeed, if the costs of the policy are similar, decreasing pollution with the same amount will result in roughly the same benefit in terms of innovation output.

While we see our findings as relevant to inform cost-benefit analyses leading to abatement strategies, it is important to stress two limitations of our study. First, we are not able to affirm the importance of different potential mechanisms behind our results. Air pollution may reduce inventive productivity by reducing the hours worked, or by reducing output conditional on hours worked. Because different mechanisms have different implications for abatement policy, it is important to disentangle them in future work. Second, our estimates may be overly conservative. Not all innovative activity is captured in patents. Many innovations are kept secret and do not show up in patent records. In addition, our back-of-the-envelope calculation did not account for the economic value of scientific output and obscures further spillover margins of innovation identified in the literature, which are hard to measure. With these drawbacks in mind, we hope this paper is a useful contribution to the cost-benefit analyses underlying rational abatement policies. 


\section{References}

Aghion, P., Akcigit, U., Hyytinen, A., and Toivanen, O. (2017). The social origins of inventors. Technical report, National Bureau of Economic Research.

Aghion, P. and Howitt, P. (1990). A model of growth through creative destruction. Technical report, National Bureau of Economic Research.

Aragón, F. M., Miranda, J. J., and Oliva, P. (2017). Particulate matter and labor supply: The role of caregiving and non-linearities. Journal of Environmental Economics and Management, 86:295-309.

Arceo, E., Hanna, R., and Oliva, P. (2016). Does the effect of pollution on infant mortality differ between developing and developed countries? evidence from mexico city. The Economic Journal, 126(591):257-280.

Archsmith, J., Heyes, A., and Saberian, S. (2018). Air quality and error quantity: Pollution and performance in a high-skilled, quality-focused occupation. Journal of the Association of Environmental and Resource Economists, 5(4):827-863.

Bell, A., Chetty, R., Jaravel, X., Petkova, N., and Van Reenen, J. (2019). Who becomes an inventor in america? the importance of exposure to innovation. The Quarterly Journal of Economics, 134(2):647-713.

Bloom, N., Schankerman, M., and Reenen, J. V. (2013). Identifying Technology Spillovers and Product Market Rivalry. Econometrica, 81(4):1347-1393.

Chang, T., Zivin, J. G., Gross, T., and Neidell, M. (2016). Particulate pollution and the productivity of pear packers. American Economic Journal: Economic Policy, 8(3):141169.

Chang, T. Y., Zivin, J. G., Gross, T., and Neidell, M. (2019). The effect of pollution on worker productivity: Evidence from call center workers in China. American Economic Journal: Applied Economics, 11(1):151-172.

Cohen, A. J., Brauer, M., Burnett, R., Anderson, H. R., Frostad, J., Estep, K., Balakrishnan, K., Brunekreef, B., Dandona, L., Dandona, R., Feigin, V., Freedman, G., Hubbell, B., Jobling, A., Kan, H., Knibbs, L., Liu, Y., Martin, R., Morawska, L., Pope, C. A., Shin, H., Straif, K., Shaddick, G., Thomas, M., van Dingenen, R., van Donkelaar, A., Vos, T., Murray, C. J., and Forouzanfar, M. H. (2017). Estimates and 25-year trends of the global burden of disease attributable to ambient air pollution: an analysis of data from the Global Burden of Diseases Study 2015. The Lancet, 389(10082):1907-1918.

Columbia University, C. f. I. E. S. I. N. C. (2018). Gridded population of the world, version 4 (gpwv4): Population count, revision 11.

Conley, T. G. (1999). Gmm estimation with cross sectional dependence. Journal of econometrics, 92(1):1-45.

Conley, T. G. (2010). Spatial econometrics. In Microeconometrics, pages 303-313. Springer. 
de Rassenfosse, G., Kozak, J., and Seliger, F. (2019). Geocoding of worldwide patent data. Scientific Data, 6(1):260.

Dechezleprêtre, A., Rivers, N., and Stadler, B. (2019). The economic cost of air pollution: Evidence from europe.

Ebenstein, A., Lavy, V., and Roth, S. (2016). The long-run economic consequences of high- stakes examinations: Evidence from transitory variation in pollution. American Economic Journal: Applied Economics, 8(4):36-65.

European Commission (2020). Science, research and innovation performance of the eu 2020.

European Environment Agency (2020). Air quality in europe - 2020 report.

European Parliament and Council of the European Union (2008). Directive 2008/50/EC. OJ, L 152:1-44.

Eurostat (2017). Eurostat regional yearbook 2017.

Foreman, T. (2020). spatial_hac_iv: Stata module to estimate an instrumental variable regression, adjusting standard errors for spatial correlation, heteroskedasticity, and autocorrelation. Statistical Software Components, Boston College Department of Economics.

Gambardella, A., Harhoff, D., and Verspagen, B. (2008). The value of European patents. European Management Review, 5(2):69-84.

Garratt, J. R. (1994). The atmospheric boundary layer. Earth-Science Reviews, 37(12):89-134.

Gelaro, R., McCarty, W., Suárez, M. J., Todling, R., Molod, A., Takacs, L., Randles, C. A., Darmenov, A., Bosilovich, M. G., Reichle, R., et al. (2017). The modern-era retrospective analysis for research and applications, version 2 (merra-2). Journal of climate, 30(14):5419-5454.

Genc, D. D., Yesilyurt, C., and Tuncel, G. (2010). Air pollution forecasting in ankara, turkey using air pollution index and its relation to assimilative capacity of the atmosphere. Environmental Monitoring and Assessment, 166(1):11-27.

Gramsch, E., Cáceres, D., Oyola, P., Reyes, F., Vásquez, Y., Rubio, M., and Sánchez, G. (2014). Influence of surface and subsidence thermal inversion on pm2. 5 and black carbon concentration. Atmospheric Environment, 98:290-298.

Griliches, Z. (1990). Patent statistics as economic indicators: A survey. Journal of Economic Literature, 28(4):1661.

Hall, B. H., Jaffe, A., and Trajtenberg, M. (2005). Market value and patent citations. RAND Journal of economics, pages 16-38.

Hall, B. H., Jaffe, A. B., and Trajtenberg, M. (2001). The nber patent citation data file: Lessons, insights and methodological tools. Technical report, National Bureau of Economic Research. 
Hall, B. H., Mairesse, J., and Mohnen, P. (2010). Measuring the returns to r\&d. In Handbook of the Economics of Innovation, volume 2, pages 1033-1082. Elsevier.

Hammer, M. S., van Donkelaar, A., Li, C., Lyapustin, A., Sayer, A. M., Hsu, N. C., Levy, R. C., Garay, M. J., Kalashnikova, O. V., Kahn, R. A., et al. (2020). Global estimates and long-term trends of fine particulate matter concentrations (1998-2018). Environmental Science \&6 Technology, 54(13):7879-7890.

Hanna, R. and Oliva, P. (2015). The effect of pollution on labor supply: Evidence from a natural experiment in Mexico City. Journal of Public Economics, 122:68-79.

Hansen, L. P. (1982). Large sample properties of generalized method of moments estimators. Econometrica: Journal of the Econometric Society, pages 1029-1054.

He, J., Liu, H., and Salvo, A. (2019). Severe air pollution and labor productivity: Evidence from industrial towns in China. American Economic Journal: Applied Economics, 11(1):173-201.

Heblich, S., Trew, A., and Zylberberg, Y. (2021). East-Side Story: Historical Pollution and Persistent Neighborhood Sorting. Technical report.

Hersbach, H., Bell, B., Berrisford, P., Hirahara, S., Horányi, A., Muñoz-Sabater, J., Nicolas, J., Peubey, C., Radu, R., Schepers, D., et al. (2020). The era5 global reanalysis. Quarterly Journal of the Royal Meteorological Society, 146(730):1999-2049.

Holzworth, G. C. (1967). Mixing depths, wind speeds and air pollution potential for selected locations in the united states. Journal of applied Meteorology, 6(6):1039-1044.

Holzworth, G. C. (1972). Mixing heights, wind speeds, and potential for urban air pollution throughout the contiguous United States. US Government Printing Office.

Hou, X., Fei, D., Kang, H., Zhang, Y., and Gao, J. (2018). Seasonal statistical analysis of the impact of meteorological factors on fine particle pollution in china in 2013-2017. Natural Hazards, 93(2):677-698.

Jones, B. and Summers, L. (2020). A Calculation of the Social Returns to Innovation. Technical report, National Bureau of Economic Research, Cambridge, MA.

Khanna, G., Liang, W., Mushfiq Mobarak, A., and Song, R. (2021). The Productivity Consequences of Pollution-Induced Migration in China. Technical report.

Kogan, L., Papanikolaou, D., Seru, A., and Stoffman, N. (2017). Technological Innovation, Resource Allocation, and Growth. The Quarterly Journal of Economics, 132(2):665-712.

Koolen, C. D. and Rothenberg, G. (2019). Air pollution in europe. ChemSusChem, $12(1): 164$.

Künn, S., Palacios, J., and Pestel, N. (2019). Indoor Air Quality and Cognitive Performance. Technical report. 
Landrigan, P. J., Fuller, R., Acosta, N. J., Adeyi, O., Arnold, R., Basu, N. N., Baldé, A. B., Bertollini, R., Bose-O'Reilly, S., Boufford, J. I., Breysse, P. N., Chiles, T., Mahidol, C., Coll-Seck, A. M., Cropper, M. L., Fobil, J., Fuster, V., Greenstone, M., Haines, A., Hanrahan, D., Hunter, D., Khare, M., Krupnick, A., Lanphear, B., Lohani, B., Martin, K., Mathiasen, K. V., McTeer, M. A., Murray, C. J., Ndahimananjara, J. D., Perera, F., Potočnik, J., Preker, A. S., Ramesh, J., Rockström, J., Salinas, C., Samson, L. D., Sandilya, K., Sly, P. D., Smith, K. R., Steiner, A., Stewart, R. B., Suk, W. A., van Schayck, O. C., Yadama, G. N., Yumkella, K., and Zhong, M. (2018). The Lancet Commission on pollution and health.

Lin, W. and Wooldridge, J. M. (2019). Testing and correcting for endogeneity in nonlinear unobserved effects models. In Panel Data Econometrics, pages 21-43. Elsevier.

Morrison, G., Riccaboni, M., and Pammolli, F. (2017). Disambiguation of patent inventors and assignees using high-resolution geolocation data. Scientific data, 4(1):1-21.

Muñoz-Sabater, J. (2019). Era5-land hourly data from 2001 to present.

Nauze, A. L., Severnini, E. R., and John Heinz, H. (2021). Air Pollution and Adult Cognition: Evidence from Brain Training.

Nordhaus, W. (2004). Schumpeterian Profits in the American Economy: Theory and Measurement. Technical report, National Bureau of Economic Research, Cambridge, MA.

Pearl, J. (2009). Causality. Cambridge university press.

Power, M. C., Adar, S. D., Yanosky, J. D., and Weuve, J. (2016). Exposure to air pollution as a potential contributor to cognitive function, cognitive decline, brain imaging, and dementia: a systematic review of epidemiologic research. Neurotoxicology, 56:235-253.

Ravenscraft, D. and Scherer, F. M. (1982). The lag structure of returns to research and development. Applied Economics, 14:603-620.

Romer, P. M. (1990). Endogenous technological change. Journal of political Economy, 98(5, Part 2):S71-S102.

Scherer, F. M. (1965). Corporate inventive output, profits, and growth. Journal of Political Economy, 73(3):290-297.

Schmookler, J. (1966). Invention and economic growth. Harvard University Press.

Stafford, T. M. (2015). Indoor air quality and academic performance. Journal of Environmental Economics and Management, 70:34-50.

Stock, J. and Yogo, M. (2002). Testing for weak instruments in linear iv regression. Technical report, National Bureau of Economic Research, Inc.

Stull, R. B. (1988). An Introduction to Boundary Layer Meteorology, volume 13. Springer Science \& Business Media.

Tobler, W. R. (1970). A computer movie simulating urban growth in the detroit region. Economic geography, 46(sup1):234-240. 
Torssander, J. and Erikson, R. (2009). Stratification and Mortality-A Comparison of Education, Class, Status, and Income. European Sociological Review, 26(4):465-474.

Torvik, V. I. (2015). Mapaffil: A bibliographic tool for mapping author affiliation strings to cities and their geocodes worldwide. In D-Lib magazine: the magazine of the Digital Library Forum, volume 21. NIH Public Access.

Trajtenberg, M. (1990). A penny for your quotes: patent citations and the value of innovations. The Rand journal of economics, pages 172-187.

Underwood, E. (2017). The Polluted Brain. Science, 355(6323):342-345.

US EPA (US Environmental Protection Agency) (1997). 40 cfr part 50. national ambient air quality standards for particulate matter. final rule. Fed Reg 62, pages 38652-38460.

Vallero, D. (2014). Chapter 3 - the science of air pollution. In Vallero, D., editor, Fundamentals of Air Pollution (Fifth Edition), pages 43-81. Academic Press, Boston, fifth edition edition.

Van Donkelaar, A., Martin, R. V., Li, C., and Burnett, R. T. (2019). Regional estimates of chemical composition of fine particulate matter using a combined geoscience-statistical method with information from satellites, models, and monitors. Environmental science \& technology, 53(5):2595-2611.

WHO (2016). Ambient air pollution: a global assessment of exposure and burden of disease. World Health Organization.

Wooldridge, J. M. (1999). Distribution-free estimation of some nonlinear panel data models. Journal of Econometrics, 90(1):77-97.

Xu, G., Jiao, L., Zhang, B., Zhao, S., Yuan, M., Gu, Y., Liu, J., Tang, X., et al. (2017). Spatial and temporal variability of the pm2. $5 / \mathrm{pm} 10$ ratio in wuhan, central china. Aerosol and Air Quality Research, 17(3):741-751.

Yang, S., Wolfram, D., and Wang, F. (2017). The relationship between the author byline and contribution lists: a comparison of three general medical journals. Scientometrics, 110(3):1273-1296.

Zacchia, P. (2018). Benefiting colleagues but not the city: Localized effects from the relocation of superstar inventors. Research Policy, 47(5):992-1005.

Zivin, J. G. and Neidell, M. (2012). The impact of pollution on worker productivity. American Economic Review, 102(7):3652-3673.

Zivin, J. G. and Neidell, M. (2018). Air pollution's hidden impacts. Science, 359(6371):3940. 


\section{Appendices}

\section{A Descriptive statistics}

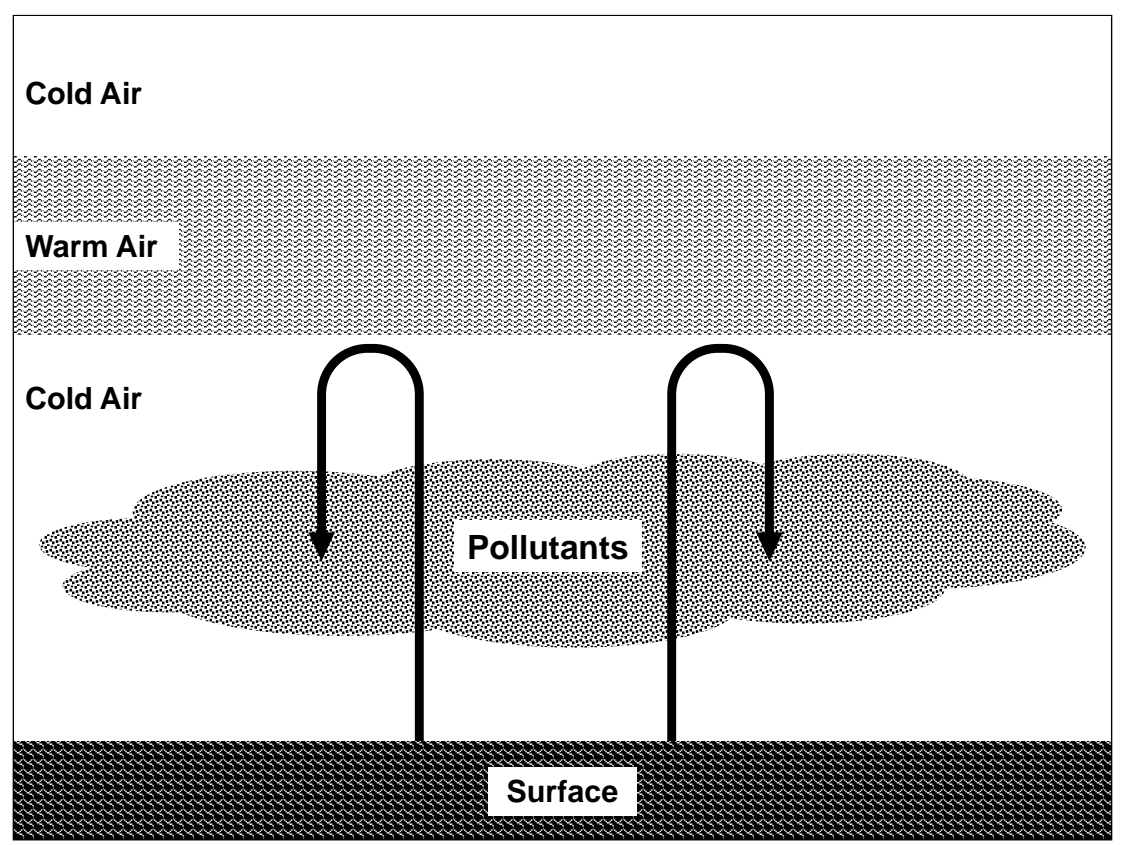

Figure 1: Thermal Inversion

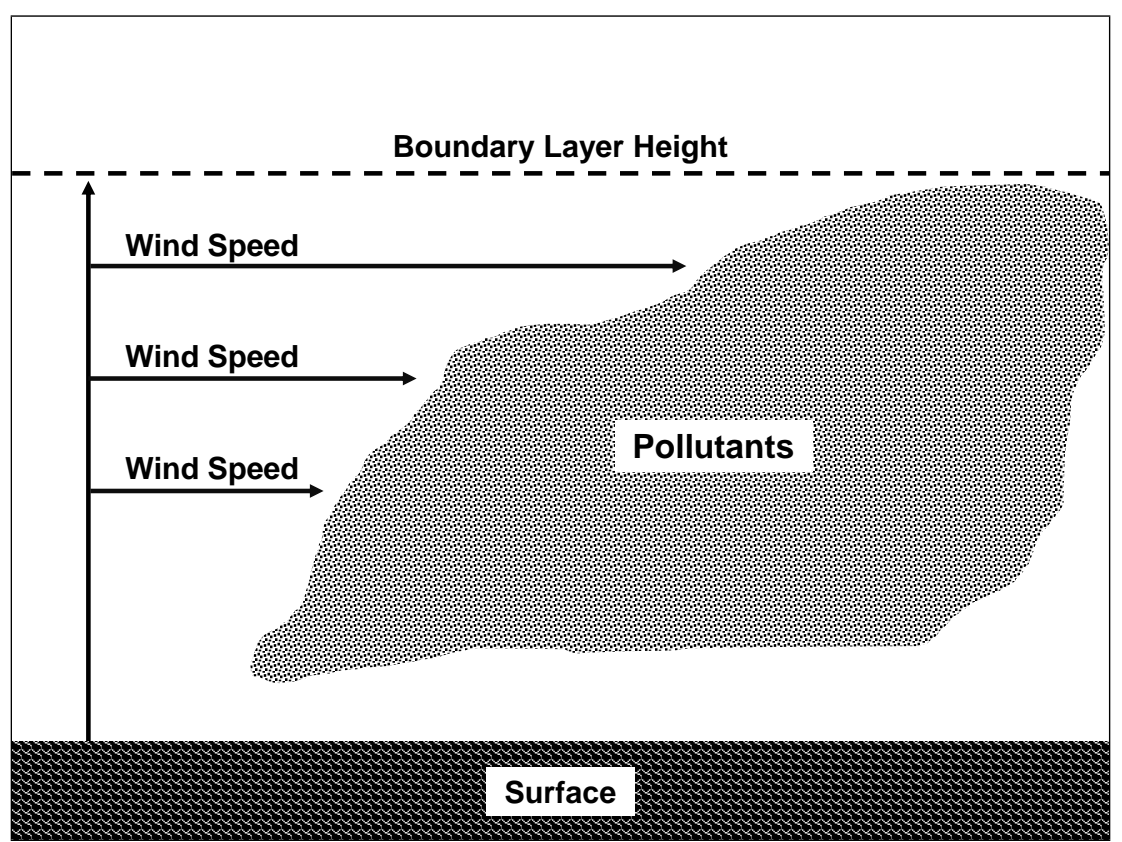

Figure 2: Ventilation Coefficient 


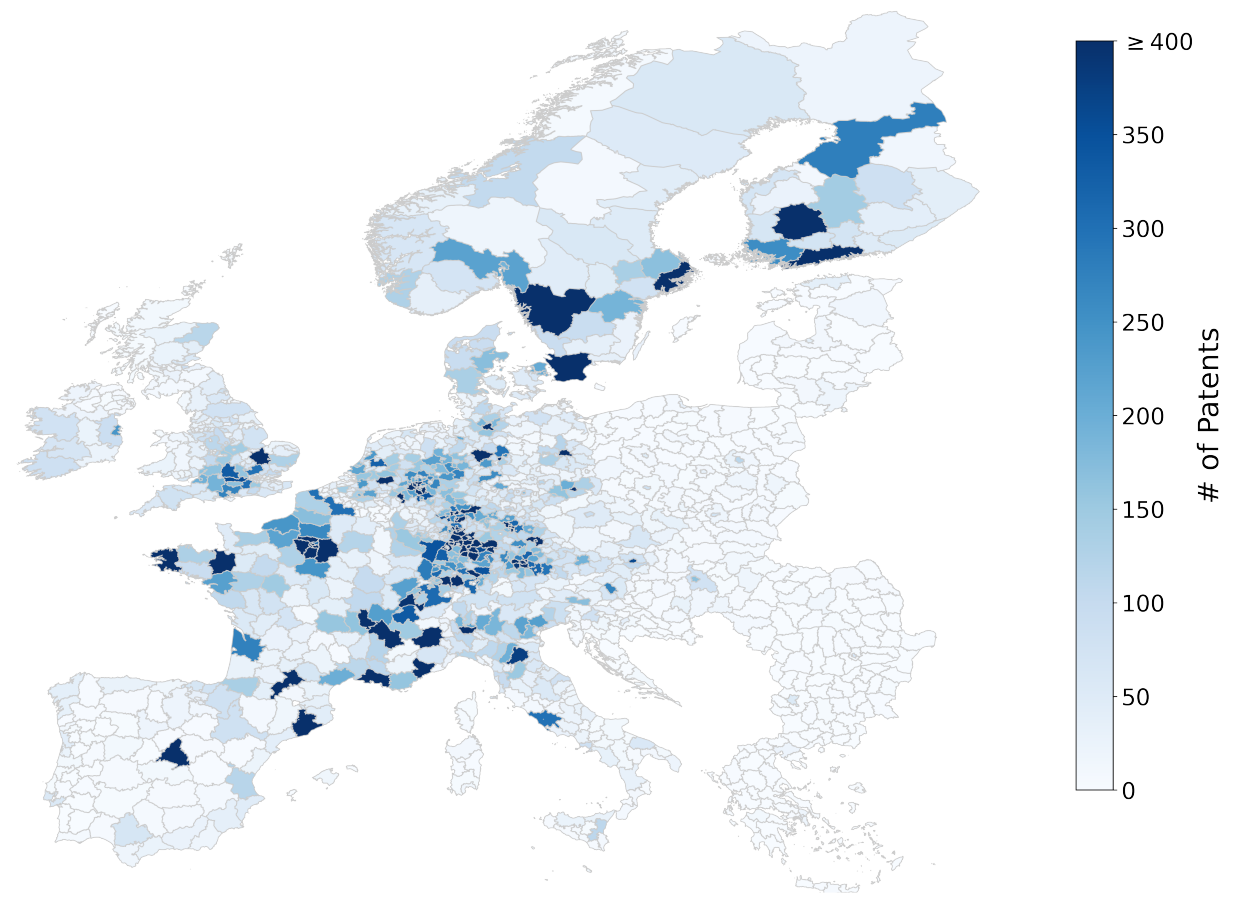

Figure 3: Annual average number of patent filings per NUTS-3 region

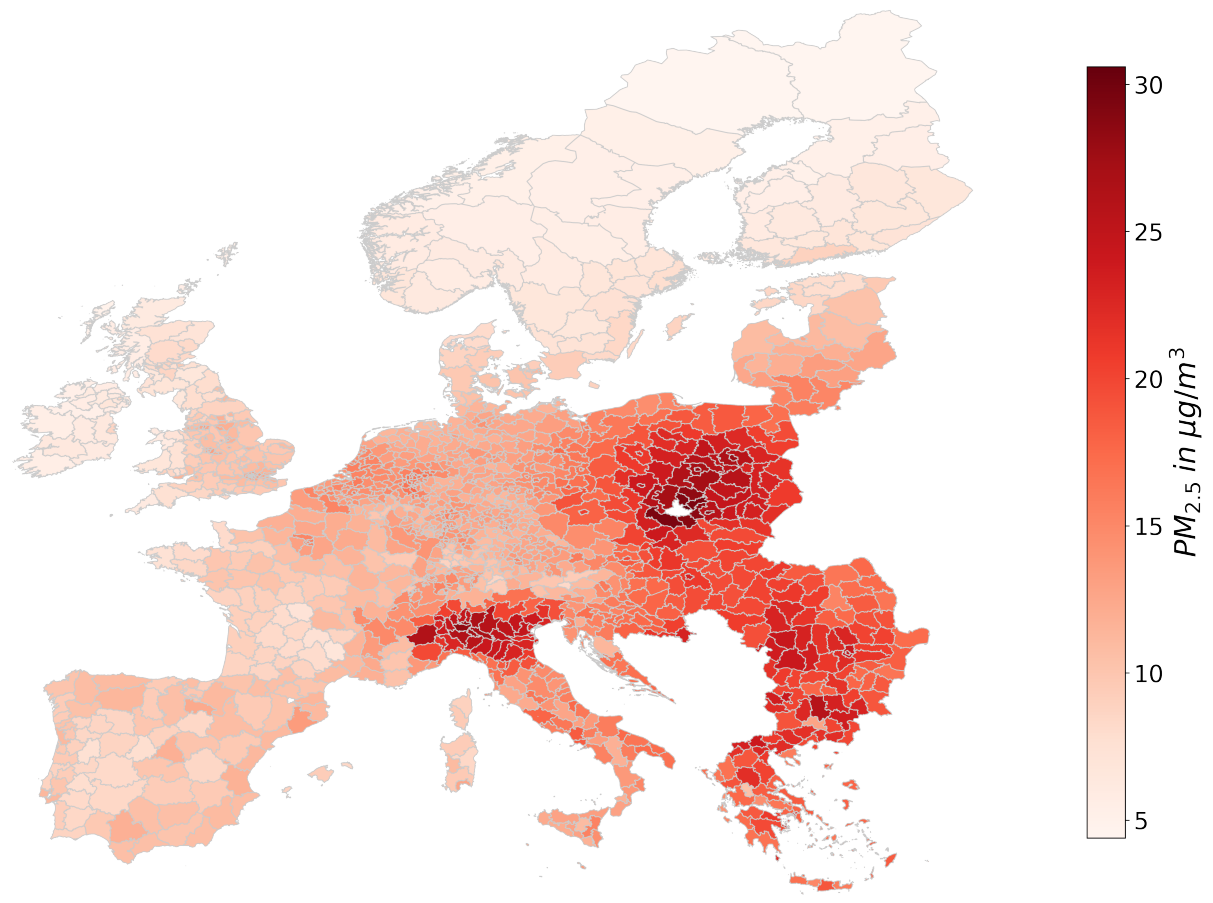

Figure 4: Annual average $P M_{2.5}$ level per NUTS-3 region 


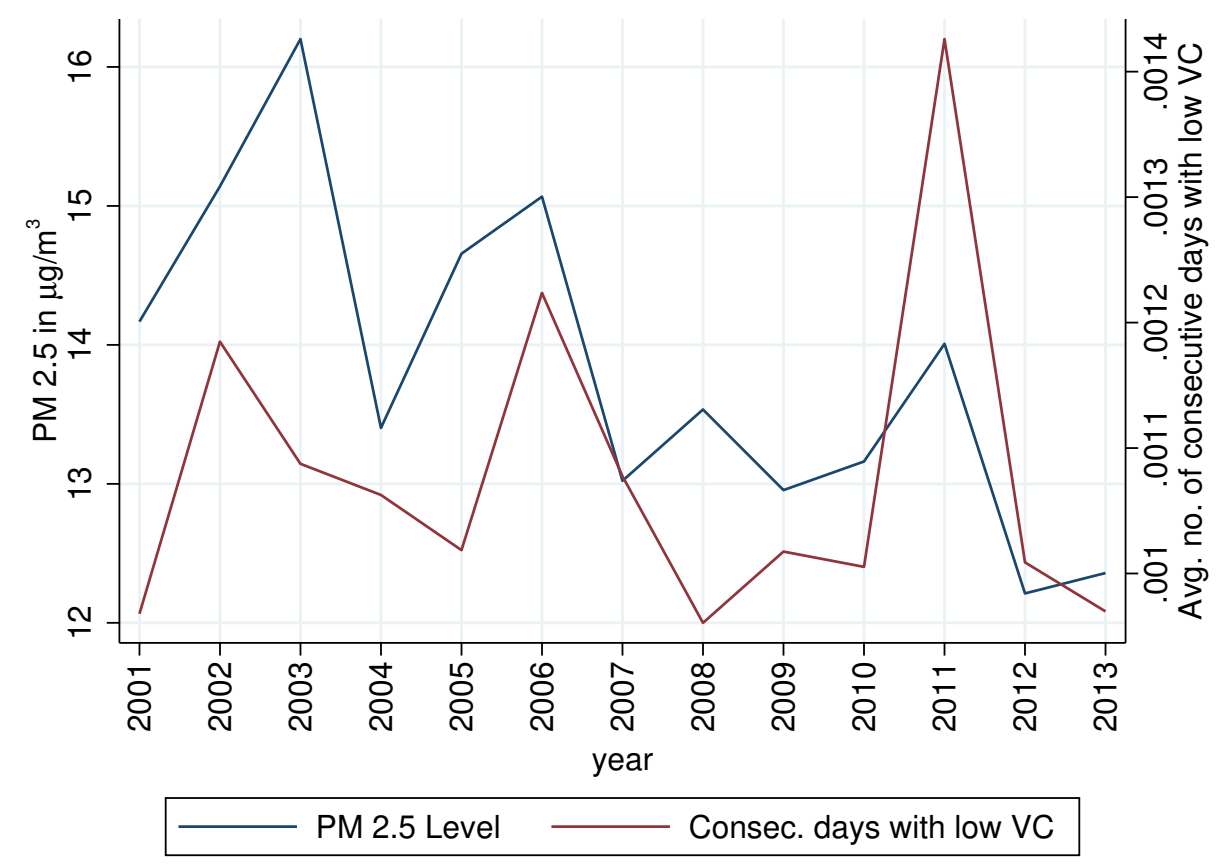

(a) Ventilation Capability and $P M_{2.5}$

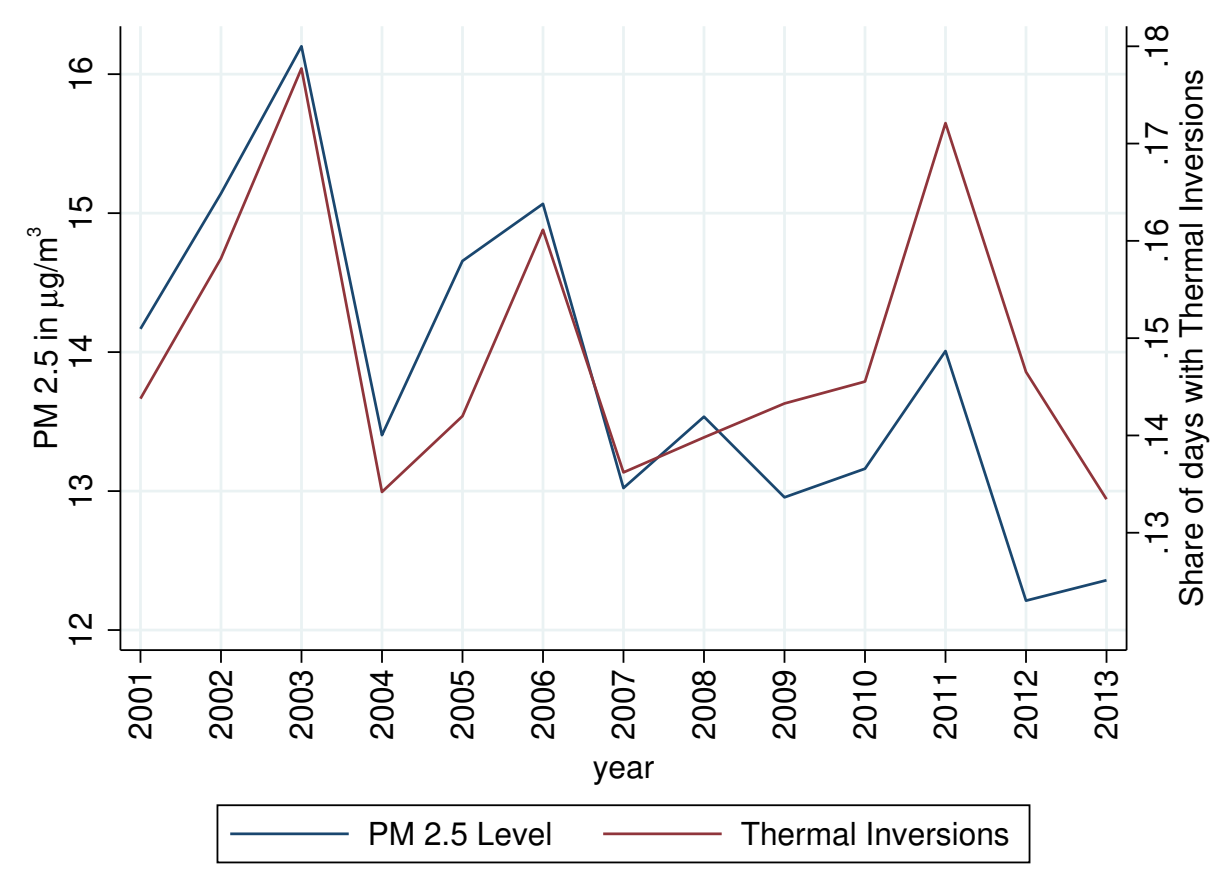

(b) Thermal Inversions and $P M_{2.5}$

Figure 5: Correlation between IV and $P M_{2.5}$ 


\section{B Summary statistics}

Table 1: Summary statistics

\begin{tabular}{lcccccc}
\hline \hline & $\mathrm{N}$ & Mean & Std. Dev. & 10th & 50 th & 90 th \\
\hline Nb. patent filings & 15540 & 109.68 & 224.96 & 3 & 41 & 261 \\
Nb. 5-year fw. cites & 15540 & 183.93 & 397.88 & 2 & 58 & 448 \\
Nb. fw. cites normalized & 15540 & 39.81 & 80.63 & 0.45 & 13.79 & 97.60 \\
Population $($ in $t h d)$ & 13706 & 384.39 & 436.57 & 94.33 & 269.63 & 734.27 \\
Pop-weighted PM 2.5 & 15218 & 13.75 & 4.83 & 8.41 & 12.99 & 20.61 \\
Nb. thermal inversions & 15300 & 54.88 & 32.83 & 13 & 52 & 101 \\
Share thermal inversions & 15300 & 0.15 & 0.09 & 0.04 & 0.14 & 0.28 \\
Ventilation Coefficient $\left(\mathrm{m}^{2} / \mathrm{s}\right)$ & 15156 & 1649.30 & 803.33 & 598 & 1620 & 2662 \\
Avg consecutive days with low VC & 15156 & 0.00 & 0.0003 & 0.0008 & 0.0010 & 0.0015 \\
Surface pressure $(P a)$ & 15156 & 97979.40 & 3463.07 & 93817 & 98981 & 101093 \\
Relative humidty $(\%)$ & 15300 & 0.74 & 0.06 & 0.64 & 0.74 & 0.81 \\
Temperature $(K)$ & 15156 & 283.05 & 2.66 & 280 & 283 & 286 \\
Wind speed $(m / s)$ & 15156 & 2.49 & 0.94 & 1.23 & 2.47 & 3.62 \\
Precipitation $(m)$ & 15156 & 0.13 & 0.04 & 0.09 & 0.12 & 0.18 \\
\hline$N$ & 15540 & & & & & \\
\hline \hline
\end{tabular}

Summary statistics of 1288 NUTS-regions for 30 countries observed over the period $2001-2012$. Our data includes all EU member states (+ United Kingdom) and EFTA countries. Iceland and Cyprus are not included because both countries are outside the geographical boundaries of our dataset.

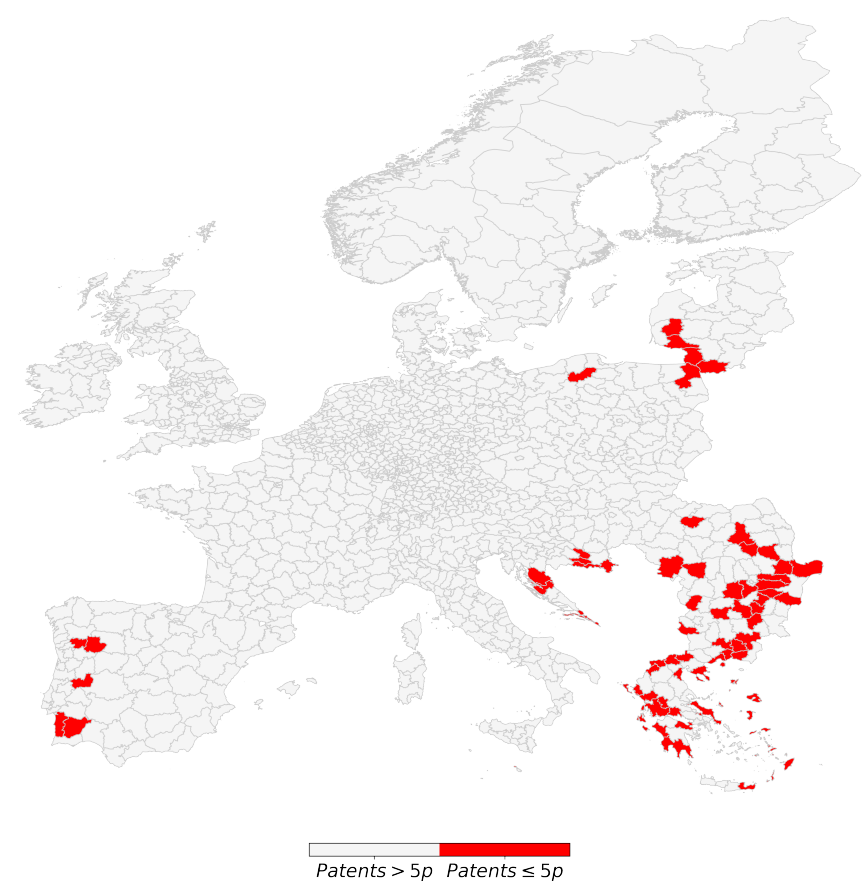

Figure 6: Dropped NUTS-3 regions with total number of patent filings equal or below the 5 th percentile 


\section{Main Results}

Table 2: $P M_{2.5}$ on the number of patent applications

\begin{tabular}{|c|c|c|c|c|c|c|c|}
\hline \multirow[b]{2}{*}{ Dep. Variable: } & \multirow{2}{*}{$\frac{\text { OLS }}{\log (\text { Patents })}$} & \multicolumn{2}{|c|}{ IV with TI } & \multicolumn{2}{|c|}{ IV with VC } & \multicolumn{2}{|c|}{ IV with TI \& VC } \\
\hline & & Log(Patents) & $P M 2.5$ & Log(Patents) & $P M 2.5$ & Log(Patents) & $P M 2.5$ \\
\hline$P M 2.5$ & $\begin{array}{l}-0.0053 \\
(0.0037)\end{array}$ & $\begin{array}{c}-0.092^{*} \\
(0.047)\end{array}$ & & $\begin{array}{c}-0.11^{* *} \\
(0.050)\end{array}$ & & $\begin{array}{c}-0.10^{* * *} \\
(0.036)\end{array}$ & \\
\hline Share Inversions & & & $\begin{array}{c}3.72^{* * *} \\
(0.52)\end{array}$ & & & & $\begin{array}{c}3.66^{* * *} \\
(0.51)\end{array}$ \\
\hline Share low $V C$ & & & & & $\begin{array}{c}260.4^{* * * *} \\
(39.3) \\
\end{array}$ & & $\begin{array}{c}255.6^{* * * *} \\
(39.5) \\
\end{array}$ \\
\hline NUTS-3 FE & YES & YES & & YES & & YES & \\
\hline Country-Year FE & YES & YES & & YES & & YES & \\
\hline Controls & YES & YES & & YES & & YES & \\
\hline KP F-stat. & & 52.1 & & 43.9 & & 44.9 & \\
\hline Hansen J stat. P-Val & & & & & & 0.78 & \\
\hline $\mathrm{N}$ & 12924 & 12924 & 12924 & 12924 & 12924 & 12924 & 12924 \\
\hline
\end{tabular}

This table presents the results of regressing $P M_{2.5}$ concentration on the annual number of patent applications per NUTS-3 region. The first column shows the results for the OLS regression without using IVs. The second and third column show the second- and first-stage results by using thermal inversions as IV. The fourth and fifth column show the second- and first-stage results by using ventilation capability as IV. The last two columns show the second- and first-stage results by using both IV's. Share of Inversions measures the number of days in which thermal inversions occur normalized by the total number of days per year. Share of low $V C$ measures the annual average length of consecutive days with a low ventilation coefficient normalized by the total number of days per year. We define a low ventilation coefficient as any daily average ventilation coefficient that is equal or below the $20 t h$ percentile of the distribution of daily average ventilation coefficients within a NUTS-3 region. Standard errors are reported in parentheses and clustered at the NUTS-3 level.

${ }^{*} p<0.10,{ }^{* *} p<0.05,{ }^{* * *} p<0.01$

Table 3: Summary for the predicted $P M_{2.5}$ concentrations for the regressions shown in table 2

\begin{tabular}{lcccccc}
\hline \hline & N & Mean & Std. Dev. & Min & 50th & Max \\
\hline Predicted $P M_{2.5}$ with TI & 12924 & 13.75 & 0.33 & 13.20 & 13.71 & 15.04 \\
Predicted $P M_{2.5}$ with VC & 12924 & 13.75 & 0.09 & 13.57 & 13.73 & 14.98 \\
Predicted $P M_{2.5}$ with both IV's & 12924 & 13.75 & 0.34 & 13.07 & 13.72 & 15.51 \\
\hline \hline
\end{tabular}

Predicted $\mathbf{P M}_{\mathbf{2 . 5}}$ with TI refers to the predicted $P M_{2.5}$ concentration of regressing $P M_{2.5}$ on Thermal Inversions (Table 2 third column) by setting controls to mean.

Predicted $\mathbf{P M}_{\mathbf{2 . 5}}$ with VC refers to predicted $P M_{2.5}$ concentration of regressing $P M_{2.5}$ on Ventilation Capability (Table 2 fifth column) by setting controls to mean.

Predicted $\mathbf{P M}_{\mathbf{2 . 5}}$ with both IVs refers to predicted $P M_{2.5}$ concentration of regressing $P M_{2.5}$ on Thermal Inversions and Ventilation Capability (Table 2 seventh column) by setting controls to mean. 


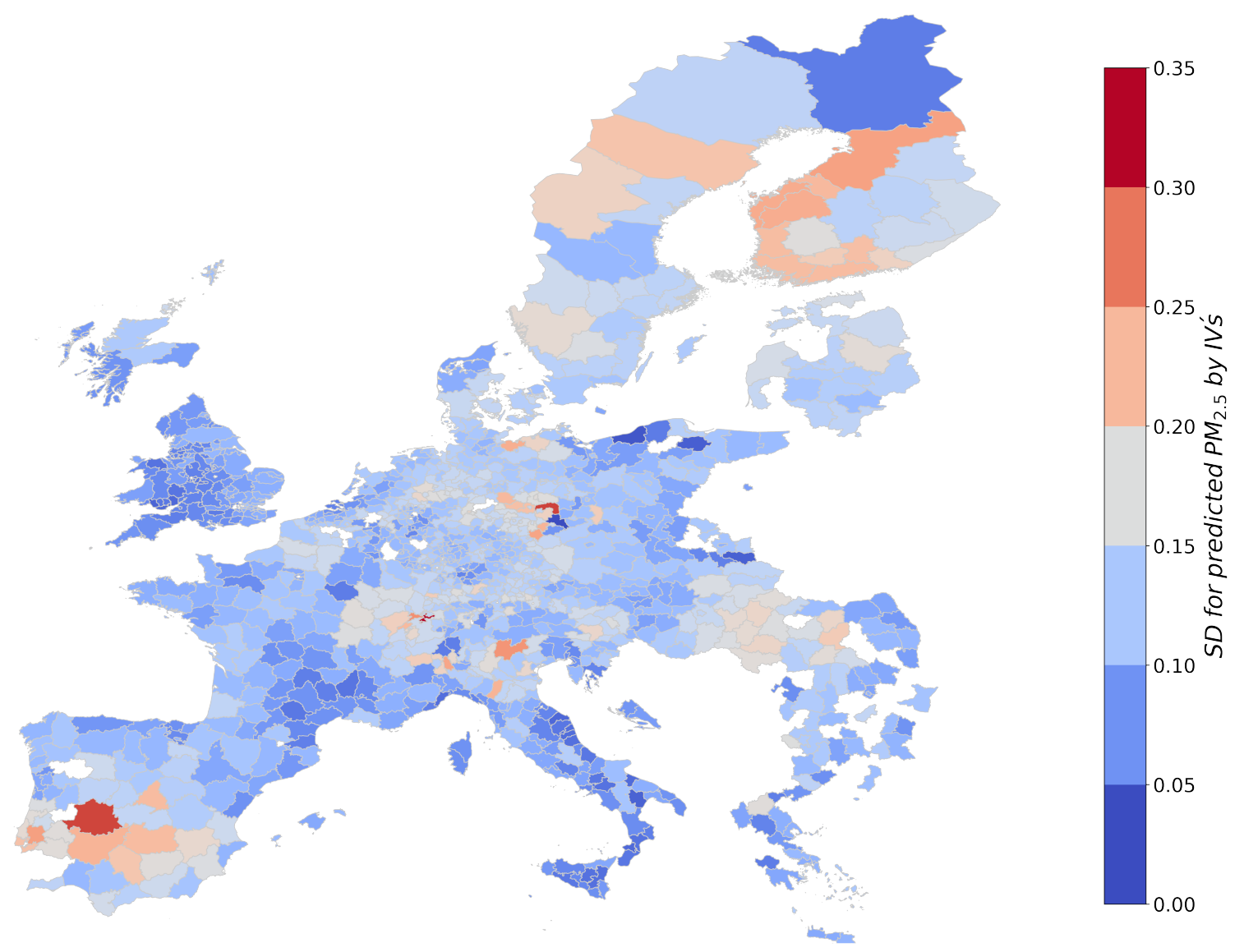

Figure 7: Variation in predicted $P M_{2.5}$ concentration by NUTS-3 region 
Table 4: Split sample based on regions median $P M_{2.5}$ concentration

\begin{tabular}{|c|c|c|c|c|}
\hline \multirow[b]{2}{*}{ Dep. Variable: } & \multicolumn{2}{|c|}{ Low PM 2.5 below Median } & \multicolumn{2}{|c|}{ High PM 2.5 above Median } \\
\hline & Log(Patents) & $P M 2.5$ & Log(Patents) & $P M 2.5$ \\
\hline$P M 2.5$ & $\begin{array}{c}-0.049 \\
(0.049)\end{array}$ & & $\begin{array}{c}-0.15^{* *} \\
(0.067)\end{array}$ & \\
\hline Share Inversions & & $\begin{array}{c}3.17 * * * \\
(0.52)\end{array}$ & & $\begin{array}{c}3.89 * * * \\
(0.94)\end{array}$ \\
\hline Share low VC & & $\begin{array}{c}225.7^{* * *} \\
(44.9)\end{array}$ & & $\begin{array}{c}210.0^{* * *} \\
(63.4)\end{array}$ \\
\hline Mean \# Patents & 89.19 & & 130.81 & \\
\hline Mean PM 2.5 & 10.49 & & 17.05 & \\
\hline NUTS-3 FE & YES & & YES & \\
\hline Country-Year FE & YES & & YES & \\
\hline KP F-stat. & 32.1 & & 14.0 & \\
\hline Hansen J stat. P-Val & 0.59 & & 0.94 & \\
\hline $\mathrm{N}$ & 6605 & 6605 & 6307 & 6307 \\
\hline
\end{tabular}

This table presents the results for the split sample into high- and low-polluted NUTS-3 regions. The first two columns show the second- and first-stage results for the sub-sample of low polluted NUTS-3 regions with a mean $P M_{2.5}$ concentration below the median of all regions. The last two columns show the second- and first-stage results for the sub-sample of high polluted NUTS-3 regions with a mean $P M_{2.5}$ concentration above the median of all regions. Share of Inversions measures the number of days in which thermal inversions occur normalized by the total number of days per year. Share of low VC measures the annual average length of consecutive days with a low ventilation coefficient normalized by the total number of days per year. We define a low ventilation coefficient as any daily average ventilation coefficient that is equal or below the $20 t h$ percentile of the distribution of daily average ventilation coefficients within a NUTS-3 region. Standard errors are reported in parentheses and clustered at the NUTS-3 level.

${ }^{*} p<0.10,{ }^{* *} p<0.05,{ }^{* * *} p<0.01$ 
Table 5: Split sample based on Urban-Rural classification

\begin{tabular}{|c|c|c|c|c|c|c|}
\hline \multirow[b]{2}{*}{ Dep. Variable: } & \multicolumn{2}{|c|}{ Predominantly Urban } & \multicolumn{2}{|c|}{ Intermediate } & \multicolumn{2}{|c|}{ Predominantly Rural } \\
\hline & Log(Patents) & $P M 2.5$ & Log(Patents) & $P M 2.5$ & Log(Patents) & $P M 2.5$ \\
\hline$P M 2.5$ & $\begin{array}{c}-0.092^{* *} \\
(0.043)\end{array}$ & & $\begin{array}{c}-0.17^{* * *} \\
(0.062)\end{array}$ & & $\begin{array}{r}-0.0033 \\
(0.094)\end{array}$ & \\
\hline Share Inversions & & $\begin{array}{c}5.43^{* * *} \\
(1.08)\end{array}$ & & $\begin{array}{c}2.66^{* * *} \\
(0.80)\end{array}$ & & $\begin{array}{c}3.91^{* * *} \\
(0.76)\end{array}$ \\
\hline Share low VC & & $\begin{array}{c}303.7^{* * * *} \\
(83.3) \\
\end{array}$ & & $\begin{array}{c}238.2^{* * * *} \\
(57.4) \\
\end{array}$ & & $\begin{array}{c}148.7^{* *} \\
(67.9)\end{array}$ \\
\hline Mean \# Patents & 208.26 & & 96.59 & & 40.84 & \\
\hline Mean PM 2.5 & 14.14 & & 14.15 & & 13.06 & \\
\hline NUTS-3 FE & YES & & YES & & YES & \\
\hline Year FE & YES & & YES & & YES & \\
\hline KP F-stat. & 18.9 & & 13.7 & & 16.2 & \\
\hline Hansen J stat. P-Val & 0.60 & & 0.56 & & 0.25 & \\
\hline $\mathrm{N}$ & 3370 & 3370 & 5746 & 5746 & 3704 & 3704 \\
\hline
\end{tabular}

This table presents the results for the split sample into predominantly rural, intermediate and predominantly urban areas. The first two columns show the second- and first-stage results for the sub-sample of NUTS-3 regions classified as predominantly urban areas. The third and fourth column show the secondand first-stage results for the sub-sample of NUTS-3 regions classified as intermediate areas. The last two columns show the second- and first-stage results for the sub-sample of NUTS-3 regions classified as rural areas. Share of Inver sions measures the number of days in which thermal inversions occur normalized by the total number of days per year. Share of low $V C$ measures the annual average length of consecutive days with a low ventilation coefficient normalized by the total number of days per year. We define a low ventilation coefficient as any daily average ventilation coefficient that is equal or below the 20th percentile of the distribution of daily average ventilation coefficients within a NUTS-3 region. Standard errors are reported in parentheses and clustered at the NUTS-3 level.

$* p<0.10, * * p<0.05, * * * p<0.01$

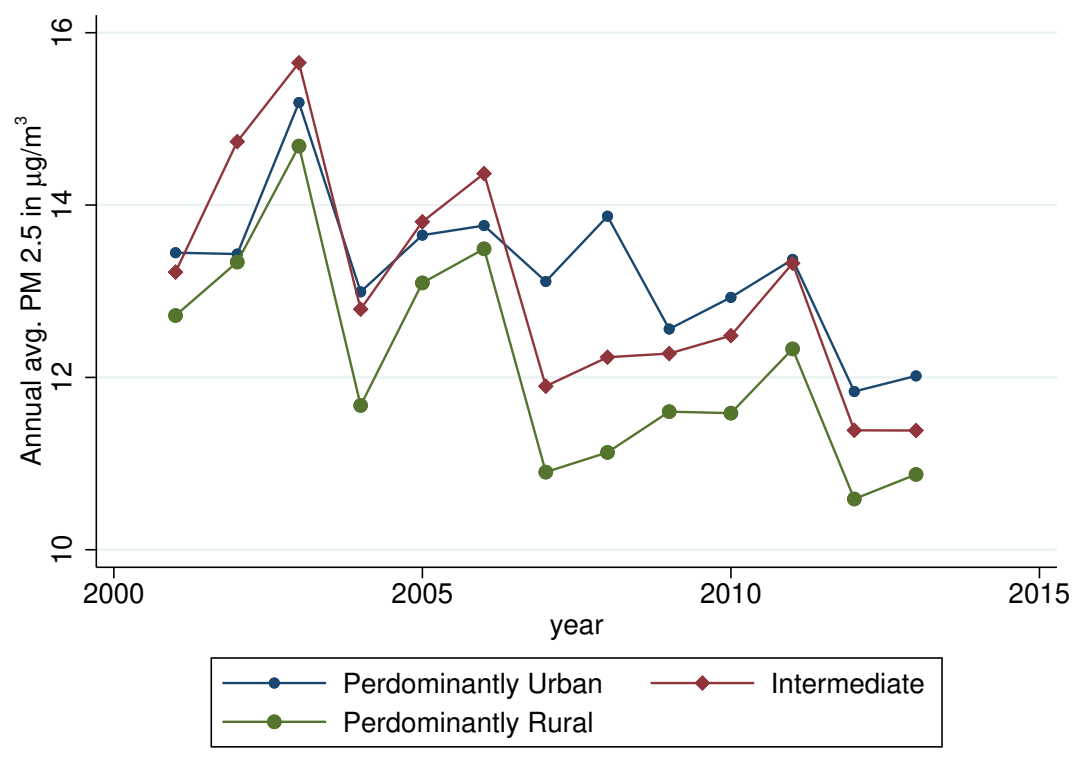

Figure 8: Annual average $P M_{2.5}$ concentration by Urban-Rural classification 


\section{Mechanisms}

Table 6: Supplementary summary statistics

\begin{tabular}{lcccccc}
\hline \hline & $\mathrm{N}$ & Mean & Std. Dev. & 10th & 50 th & 90 th \\
\hline Nb. migrating inventors & 16380 & 1.92 & 5.50 & 0 & 0 & 5 \\
Nb. (patents) migrating inventors & 16380 & 7.66 & 29.76 & 0 & 0 & 19 \\
Nb. immigrating inventors & 16380 & 2.07 & 5.70 & 0 & 0 & 5 \\
Nb. (patents) immigrating inventors & 16380 & 8.13 & 29.90 & 0 & 0 & 20 \\
Nb. of publications & 16380 & 151.70 & 433.72 & 0 & 9 & 431 \\
Nb. of deaths & 14296 & 3696.36 & 3787.99 & 936 & 2695 & 7210 \\
Death rate $(\%)$ & 13898 & 1.04 & 0.20 & 0.81 & 1.02 & 1.29 \\
\hline$N$ & 16380 & & & & & \\
\hline \hline
\end{tabular}

Summary statistics of 1365 NUTS-regions for 30 countries observed over the period $2001-2012$. Our data includes all EU member states ( + United Kingdom) and EFTA countries. Iceland and Cyprus are not included because both countries are outside the geographical boundaries of our dataset. In contrast to the sample of our baseline results (table 1), we do not drop NUTS-3 regions equal or below the 5 th percentile of the distribution for total number of patent filings.

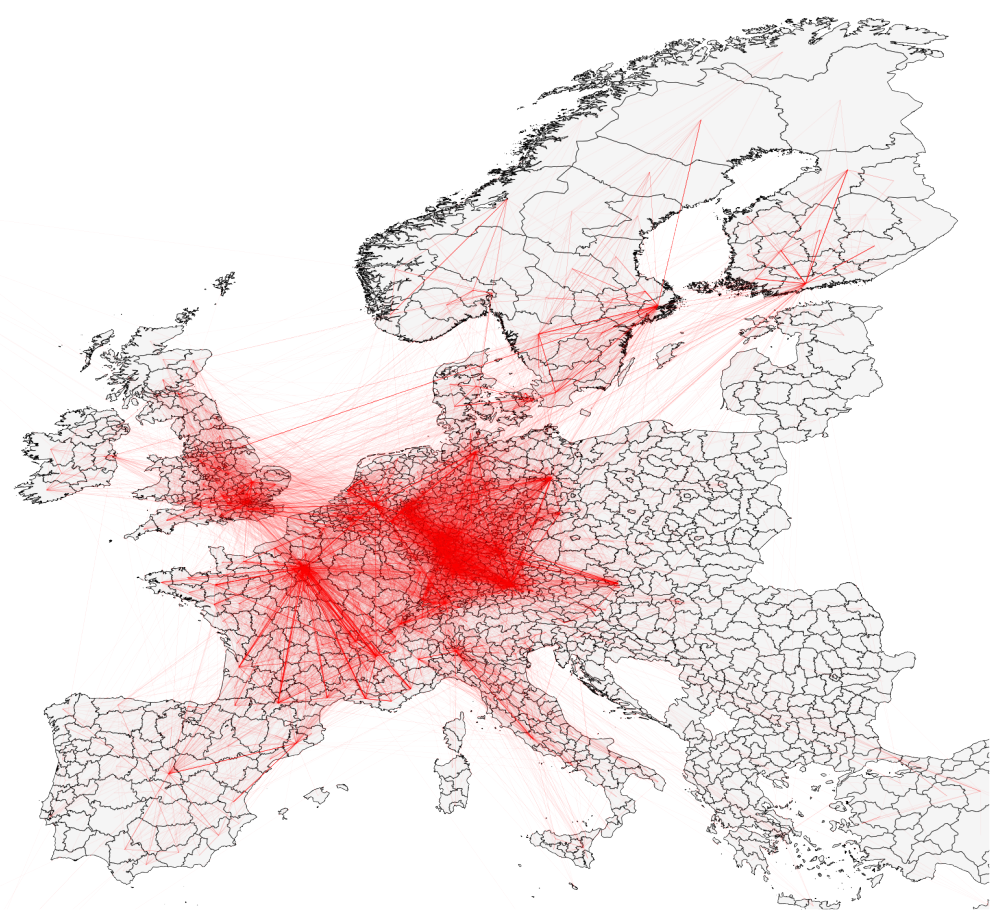

Figure 9: Inventors relocating between NUTS-3 regions for the sample period 2001-2012. Weight of line indicate relocation frequency. 


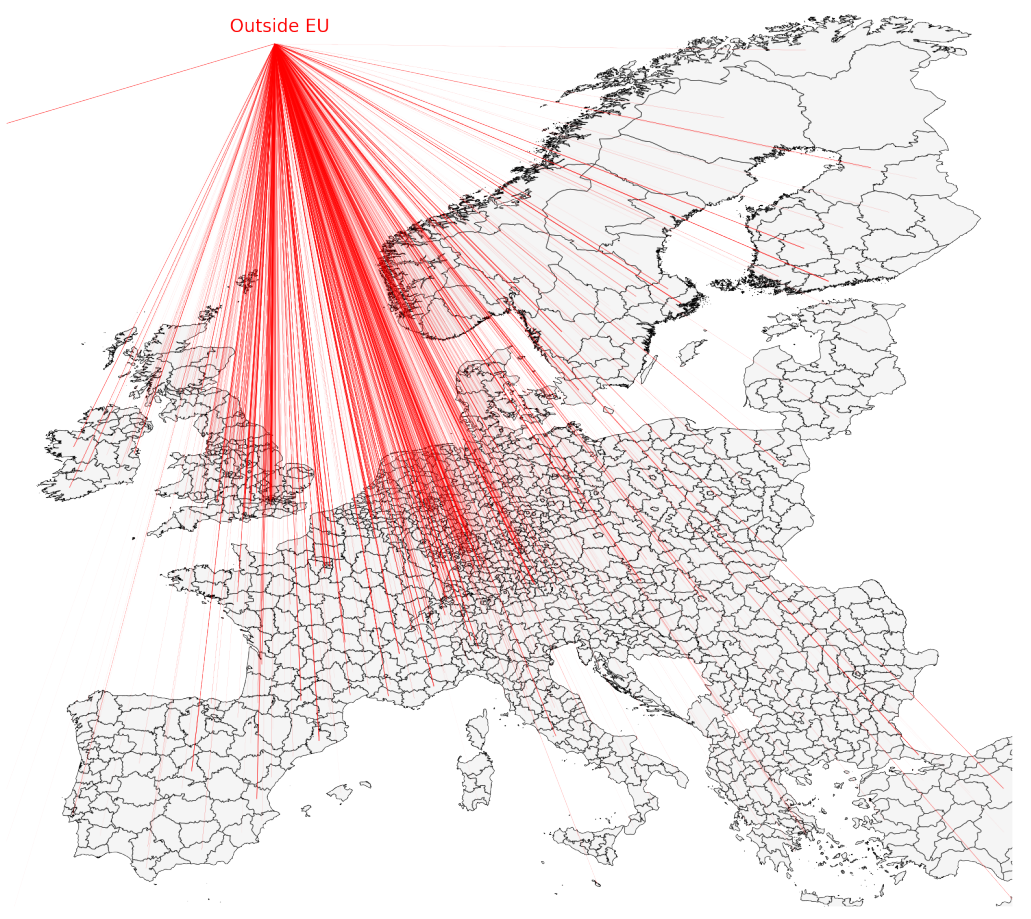

Figure 10: Inventors relocating between NUTS-3 and regions outside Europe for the sample period 2001-2012. Weight of line indicate relocation frequency.

Table 7: Migrating inventors and air pollution

\begin{tabular}{|c|c|c|c|c|c|c|}
\hline \multirow[b]{2}{*}{ Dep. Variable: } & \multirow{2}{*}{ 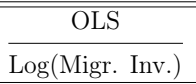 } & \multicolumn{2}{|l|}{$\overline{\mathrm{IIV}}$} & OLS & \multicolumn{2}{|l|}{ IV } \\
\hline & & Log(Migr. Inv.) & $P M 2.5$ & Log(Migr. Inv. Patents) & Log(Migr. Inv. Patents) & $P M 2.5$ \\
\hline$P M 2.5$ & $\begin{array}{c}-0.011^{* * *} \\
(0.0039)\end{array}$ & $\begin{array}{c}0.031 \\
(0.046)\end{array}$ & & $\begin{array}{l}-0.017^{* *} \\
(0.0069)\end{array}$ & $\begin{array}{c}0.027 \\
(0.084)\end{array}$ & \\
\hline Share Inversions & & & $\begin{array}{c}3.78^{* * *} \\
(0.50)\end{array}$ & & & $\begin{array}{c}3.78^{* * *} \\
(0.50)\end{array}$ \\
\hline Share low VC & & & $\begin{array}{c}227.2^{* * *} \\
(40.3)\end{array}$ & & & $\begin{array}{c}227.2^{* * *} \\
(40.3)\end{array}$ \\
\hline NUTS-3 FE & YES & YES & & YES & YES & \\
\hline Country-Year FE & YES & YES & & YES & YES & \\
\hline Controls & YES & YES & & YES & YES & \\
\hline KP F-stat. & & 42.5 & & & 42.5 & \\
\hline Hansen J stat. P-Val & & 0.25 & & & 0.27 & \\
\hline $\mathrm{N}$ & 13671 & 13671 & 13671 & 13671 & 13671 & 13671 \\
\hline
\end{tabular}

This table presents the results of regressing $P M_{2.5}$ concentration on the total number (Log(Migr. Inv.)) and patent weighted number of migrating inventors (Log(Migr.Inv. Patents)) out of NUTS-3 regions. Log(Migr.Inv. Patents) weights the number of migrating inventors by the number of patents inventors filed within 5 year before the relocation. The first column shows results for the OLS estimation by simply regressing the total number of migrating inventors on $P M_{25}$ concentration. The second and third columns show the second- and first-stage results by instrumenting $P M_{2.5}$ with thermal inversion and ventilation capability. The fourth column shows the OLS results for the patent weighted measure of the number of migrating inventors. The last two columns show results for same outcome variable by instrumenting $P M_{2.5}$ concentration. Share of Inversions measures the number of days in which thermal inversions occur normalized by the total number of days per year. Share of low $V C$ measures the annual average length of consecutive days with a low ventilation coefficient normalized by the total number of days per year. We define a low ventilation coefficient as any daily average ventilation coefficient that is equal or below the 20 th percentile of the distribution of daily average ventilation coefficients within a NUTS-3 region. Standard errors are reported in parentheses and clustered at the NUTS-3 level.

${ }^{*} p<0.10,{ }^{* *} p<0.05,{ }^{* * *} p<0.01$ 
Table 8: Migrating inventors and air pollution for a restricted sample where the relocation year of an inventor can be well defined

\begin{tabular}{|c|c|c|c|c|c|c|}
\hline \multirow[b]{2}{*}{ Dep. Variable: } & \multirow{2}{*}{$\frac{\text { OLS }}{\frac{\text { Log(Migr. Inv.) }}{}}$} & \multicolumn{2}{|l|}{ 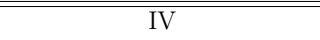 } & OLS & \multicolumn{2}{|l|}{ IV } \\
\hline & & Log(Migr. Inv.) & $P M 2.5_{t-1}$ & Log(Migr. Inv. Patents) & Log(Migr. Inv. Patents) & $P M 2.5$ \\
\hline$P M 2.5$ & $\begin{array}{c}-0.011^{* * *} \\
(0.0034)\end{array}$ & $\begin{array}{l}-0.0015 \\
(0.042)\end{array}$ & & $\begin{array}{c}-0.020^{* * *} \\
(0.0068)\end{array}$ & $\begin{array}{c}0.027 \\
(0.084)\end{array}$ & \\
\hline Share Inversions & & & $\begin{array}{c}3.78 * * * \\
(0.50)\end{array}$ & & & $\begin{array}{c}3.78^{* * *} \\
(0.50)\end{array}$ \\
\hline Share low $V C$ & & & $\begin{array}{c}227.2^{* * *} \\
(40.3)\end{array}$ & & & $\begin{array}{c}227.2^{* * *} \\
(40.3)\end{array}$ \\
\hline NUTS-3 FE & YES & YES & & YES & YES & \\
\hline Country-Year FE & YES & YES & & YES & YES & \\
\hline Controls & YES & YES & & YES & YES & \\
\hline KP F-stat. & & 42.5 & & & 42.5 & \\
\hline Hansen J stat. P-Val & & 0.27 & & & 0.27 & \\
\hline $\mathrm{N}$ & 13671 & 13671 & 13671 & 13671 & 13671 & 13671 \\
\hline
\end{tabular}

This table presents the results of regressing $P M_{2.5}$ concentration on the total number (Log(Migr.Inv.)) and patent weighted number of migrating inventors (Log(Migr.Inv. Patents)) out of NUTS-3 regions for a restricted sample where the relocation year of an inventor can be well defined.

Log(Migr.Inv. Patents) weights the number of migrating inventors by the number of patents inventors filed within 5 year before the relocation. The first column shows results for the OLS estimation by simply regressing the total number of migrating inventors on $P M_{2.5}$ concentration. The second and third columns show the second- and first-stage results by instrumenting $P M_{2.5}$ with thermal inversion and ventilation capability. The fourth column shows the OLS results for the patent weighted measure of the number of migrating inventors. The last two columns show results for same outcome variable by instrumenting $P M_{25}$ concentration. Share of Inversions measures the number of days in which thermal inversions occur normalized by the total number of days per year. Share of low $V C$ measures the annual average length of consecutive days with a low ventilation coefficient normalized by the total number of days per year. We define a low ventilation coefficient as any daily average ventilation coefficient that is equal or below the $20 t h$ percentile of the distribution of daily average ventilation coefficients within a NUTS-3 region. Standard errors are reported in parentheses and clustered at the NUTS-3 level.

$* p<0.10,{ }^{* *} p<0.05,{ }^{* * *} p<0.01$

Table 9: Immigrating inventors and air pollution

\begin{tabular}{|c|c|c|c|c|c|c|}
\hline \multirow[b]{2}{*}{ Dep. Variable: } & \multirow{2}{*}{$\frac{\text { OLS }}{\frac{\text { Log(Immigr. Inv.) }}{}}$} & \multicolumn{2}{|l|}{ 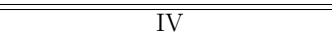 } & \multirow{2}{*}{$\frac{\text { OLS }}{\frac{\text { Log(Immigr. Inv. Patents })}{}}$} & \multicolumn{2}{|l|}{ IV } \\
\hline & & Log(Immigr. Inv.) & $P M 2.5$ & & Log(Immigr. Inv. Patents) & $P M 2.5$ \\
\hline$P M 2.5$ & $\begin{array}{l}-0.0059 \\
(0.0039)\end{array}$ & $\begin{array}{l}-0.010 \\
(0.043)\end{array}$ & & $\begin{array}{l}-0.0055 \\
(0.0068)\end{array}$ & $\begin{array}{l}-0.056 \\
(0.079)\end{array}$ & \\
\hline Share Inversions & & & $\begin{array}{c}3.78^{* * *} \\
(0.50)\end{array}$ & & & $\begin{array}{c}3.78^{* * *} \\
(0.50)\end{array}$ \\
\hline Share low $V C$ & & & $\begin{array}{c}227.2^{* * * *} \\
(40.3)\end{array}$ & & & $\begin{array}{c}227.2^{* * *} \\
(40.3)\end{array}$ \\
\hline NUTS-3 FE & YES & YES & & YES & YES & \\
\hline Country-Year FE & YES & YES & & YES & YES & \\
\hline Controls & YES & YES & & YES & YES & \\
\hline KP F-stat. & & 42.5 & & & 42.5 & \\
\hline Hansen J stat. P-Val & & 0.56 & & & 0.85 & \\
\hline $\mathrm{N}$ & 13671 & 13671 & 13671 & 13671 & 13671 & 13671 \\
\hline
\end{tabular}

This table presents the results of regressing $P M_{25}$ concentration on the total number (Log(Immigr. Inv.)) and patent weighted number of immigrating inventors (Log(Immigr. Inv. Patents)) to NUTS-3 regions. Log(Immigr. Inv. Patents) weights the number of immigrating inventors by the number of patents inventors filed within 5 year before the relocation. The first column shows results for the OLS estimation by simply regressing the total number of immigrating inventors on $P M_{2.5}$ concentration. The second and third columns show the second- and first-stage results by instrumenting $P M_{2.5}$ with thermal inversion and ventilation capability. The fourth column shows the OLS results for the patent weighted measure of the number of immigrating inventors. The last two columns show results for same outcome variable by instrumenting $P M_{25}$ concentration. Share of Inversions measures the number of days in which thermal inversions occur normalized by the total number of days per year. Share of low $V C$ measures the annual average length of consecutive days with a low ventilation coefficient normalized by the total number of days per year. We define a low ventilation coefficient as any daily average ventilation coefficient that is equal or below the $20 t h$ percentile of the distribution of daily average ventilation coefficients within a NUTS-3 region. Standard errors are reported in parentheses and clustered at the NUTS-3 level.

$* p<0.10,{ }^{* *} p<0.05,{ }^{* * *} p<0.01$ 
Table 10: Immigrating inventors and air pollution for a restricted sample where the relocation year of an inventor can be well defined

\begin{tabular}{|c|c|c|c|c|c|c|}
\hline \multirow[b]{2}{*}{ Dep. Variable: } & \multirow{2}{*}{$\frac{\text { OLS }}{\log (\text { Immigr. Inv. })}$} & \multicolumn{2}{|l|}{ IV } & OLS & \multicolumn{2}{|l|}{ IV } \\
\hline & & Log(Immigr. Inv.) & $P M 2.5_{t-1}$ & Log(Immigr. Inv. Patents) & Log(Immigr. Inv. Patents) & $P M 2.5$ \\
\hline$P M 2.5$ & $\begin{array}{c}-0.0078^{* *} \\
(0.0036)\end{array}$ & $\begin{array}{c}-0.028 \\
(0.041)\end{array}$ & & $\begin{array}{c}-0.010 \\
(0.0069)\end{array}$ & $\begin{array}{l}-0.056 \\
(0.079)\end{array}$ & \\
\hline Share Inversions & & & $\begin{array}{c}3.78^{* * *} \\
(0.50)\end{array}$ & & & $\begin{array}{c}3.78^{* * *} \\
(0.50)\end{array}$ \\
\hline Share low VC & & & $\begin{array}{c}227.2^{* * *} \\
(40.3) \\
\end{array}$ & & & $\begin{array}{c}227.2^{* * *} \\
(40.3) \\
\end{array}$ \\
\hline NUTS-3 FE & YES & YES & & YES & YES & \\
\hline Country-Year FE & YES & YES & & YES & YES & \\
\hline Controls & YES & YES & & YES & YES & \\
\hline KP F-stat. & & 42.5 & & & 42.5 & \\
\hline Hansen J stat. P-Val & & 0.64 & & & 0.85 & \\
\hline $\mathrm{N}$ & 13671 & 13671 & 13671 & 13671 & 13671 & 13671 \\
\hline
\end{tabular}

This table presents the results of regressing $P M_{2.5}$ concentration on the total number (Log(Immigr. Inv.)) and patent weighted number of immigrating inventors (Log(Immigr. Inv. Patents)) to NUTS-3 regions for a restricted sample where the relocation year of an inventor can be well defined. Log(Immigr. Inv. Patents) weights the number of immigrating inventors by the number of patents inventors filed within 5 year before the relocation. The first column shows results for the OLS estimation by simply regressing the total number of immigrating inventors on $P M_{2.5}$ concentration. The second and third columns show the second- and first-stage results by instrumenting $P M_{25}$ with thermal inversion and ventilation capability. The fourth column shows the OLS results for the patent weighted measure of the number of immigrating inventors. The last two columns show results for same outcome variable by instrumenting $P M_{2.5}$ concentration. Share of Inversions measures the number of days in which thermal inversions occur normalized by the total number of days per year. Share of low VC measures the annual average length of consecutive days with a low ventilation coefficient normalized by the total number of days per year. We define a low ventilation coefficient as any daily average ventilation coefficient that is equal or below the 20th percentile of the distribution of daily average ventilation coefficients within a NUTS-3 region. Standard errors are reported in parentheses and clustered at the NUTS-3 level.

${ }^{*} p<0.10,{ }^{* *} p<0.05,{ }^{* * *} p<0.01$

Table 11: PubMed publications and air pollution

\begin{tabular}{lcccc}
\hline \hline & OLS & & \multicolumn{2}{c}{ IV } \\
\cline { 5 - 6 } Dep. Variable: & $\log ($ PubMed $)$ & & $\log ($ PubMed $)$ & PM2.5 \\
\hline PM2.5 & -0.0023 & & $-0.086^{* *}$ & \\
& $(0.0041)$ & & $(0.042)$
\end{tabular}

$(0.0041) \quad(0.042)$

Share Inversions

Share low $V C$

\begin{tabular}{lccc}
\hline NUTS-3 FE & YES & YES & \\
Country-Year FE & YES & YES & \\
Controls & YES & YES & \\
KP F-stat. & & 42.5 & \\
Hansen J stat. P-Val & & 0.26 & \\
$\mathrm{~N}$ & 13671 & 13671 & 13671 \\
\hline \hline
\end{tabular}

This table presents the results of regressing $P M_{2.5}$ concentration on the number of journal articles listed in PubMed ( $\log ($ PubMed)). The first column shows results for the OLS estimation without using IVs. The second and third columns show the second- and first-stage results by instrumenting $P M_{2.5}$ with thermal inversion and ventilation capability. Share of Inversions measures the number of days in which thermal inversions occur normalized by the total number of days per year. Share of low $V C$ measures the annual average length of consecutive days with a low ventilation coefficient normalized by the total number of days per year. We define a low ventilation coefficient as any daily average ventilation coefficient that is equal or below the $20 t h$ percentile of the distribution of daily average ventilation coefficients within a NUTS-3 region. Standard errors are reported in parentheses and clustered at the NUTS-3 level.

$* p<0.10,{ }^{* *} p<0.05,{ }^{* * *} p<0.01$ 
Table 12: Patent citations and air pollution

\begin{tabular}{|c|c|c|c|c|}
\hline \multirow[b]{2}{*}{ Dep. Variable: } & \multicolumn{2}{|c|}{ 5-year fw. cites } & \multicolumn{2}{|c|}{ Fw. cites normalized } \\
\hline & Log(Patents) & $P M 2.5$ & Log(Patents) & $P M 2.5$ \\
\hline$P M 2.5$ & $\begin{array}{l}-0.12^{*} \\
(0.062)\end{array}$ & & $\begin{array}{c}-0.13^{* * *} \\
(0.042)\end{array}$ & \\
\hline Share Inversions & & $\begin{array}{c}3.66^{* * *} \\
(0.51)\end{array}$ & & $\begin{array}{c}3.66^{* * *} \\
(0.51)\end{array}$ \\
\hline Share low VC & & $\begin{array}{c}255.6^{* * *} \\
(39.5)\end{array}$ & & $\begin{array}{c}255.6^{* * *} \\
(39.5)\end{array}$ \\
\hline NUTS-3 FE & YES & & YES & \\
\hline Country-Year FE & YES & & YES & \\
\hline Controls & YES & & YES & \\
\hline KP F-stat. & 44.9 & & 44.9 & \\
\hline Hansen J stat. P-Val & 0.77 & & 0.87 & \\
\hline $\mathrm{N}$ & 12924 & 12924 & 12924 & 12924 \\
\hline
\end{tabular}

This table presents the results of regressing $P M_{2.5}$ concentration on the total number of forward citation for patents filed within a NUTS-3 region. The first two columns show the the second- and first-stage results by measuring forward citations patents received within a 5 -year window. The last two columns show the the second- and first-stage results by measuring the total number of forward citations normalized by the number of citations patents received with the same filing year and technical field. Share of Inversions measures the number of days in which thermal inversions occur normalized by the total number of days per year. Share of low $V C$ measures the annual average length of consecutive days with a low ventilation coefficient normalized by the total number of days per year. We define a low ventilation coefficient as any daily average ventilation coefficient that is equal or below the $20 t h$ percentile of the distribution of daily average ventilation coefficients within a NUTS-3 region. Standard errors are reported in parentheses and clustered at the NUTS-3 level.

${ }^{*} p<0.10,{ }^{* *} p<0.05,{ }^{* * *} p<0.01$ 
Table 13: Total deaths and air pollution

\begin{tabular}{|c|c|c|c|c|c|c|}
\hline \multirow[b]{2}{*}{ Dep. Variable: } & \multirow{2}{*}{$\frac{\text { OLS }}{\frac{\log (\text { Deaths })}{}}$} & \multicolumn{2}{|l|}{ IV } & \multirow{2}{*}{$\frac{\text { OLS }}{\text { Death Rate }}$} & \multicolumn{2}{|c|}{ IV } \\
\hline & & Log(Deaths) & PM2.5 & & Death Rate & PM2.5 \\
\hline$P M 2.5$ & $\begin{array}{c}-0.0011^{* * *} \\
(0.00036)\end{array}$ & $\begin{array}{c}0.0027 \\
(0.0038)\end{array}$ & & $\begin{array}{c}-0.0012^{* * *} \\
(0.00038)\end{array}$ & $\begin{array}{c}0.0028 \\
(0.0040)\end{array}$ & \\
\hline Share Inversions & & & $\begin{array}{c}3.43^{* * *} \\
(0.50)\end{array}$ & & & $\begin{array}{c}3.43^{* * *} \\
(0.50)\end{array}$ \\
\hline Share low VC & & & $\begin{array}{c}241.0^{* * *} \\
(40.7)\end{array}$ & & & $\begin{array}{c}241.0^{* * * *} \\
(40.7)\end{array}$ \\
\hline NUTS-3 FE & YES & YES & & YES & YES & \\
\hline Country-Year FE & YES & YES & & YES & YES & \\
\hline Controls & YES & YES & & YES & YES & \\
\hline KP F-stat. & & 38.6 & & & 38.6 & \\
\hline Hansen J stat. P-Val & & 0.24 & & & 0.30 & \\
\hline $\mathrm{N}$ & 13230 & 13230 & 13230 & 13230 & 13230 & 13230 \\
\hline
\end{tabular}

This table presents the results of regressing $P M_{2.5}$ concentration on the total number of death $(\log ($ Deaths $))$ and the death rate (Death Rate)) per NUTS-3 region. Death rate does not include population as control. The first and fourth columns show results for the OLS estimation without using IVs. The second and third (fifth and sixth) columns show the second- and first-stage results by instrumenting $P M_{2.5}$ with thermal inversion and ventilation capability. Share of Inversions measures the number of days in which thermal inversions occur normalized by the total number of days per year. Share of low $V C$ measures the annual average length of consecutive days with a low ventilation coefficient normalized by the total number of days per year. We define a low ventilation coefficient as any daily average ventilation coefficient that is equal or below the 20th percentile of the distribution of daily average ventilation coefficients within a NUTS-3 region. Standard errors are reported in parentheses and clustered at the NUTS-3 level.

${ }^{*} p<0.10,{ }^{* *} p<0.05,{ }^{* * *} p<0.01$ 


\section{E Robustness}

Table 14: Poisson fixed effects regression

\begin{tabular}{|c|c|c|}
\hline & Poisson & Poisson CF \\
\hline Dep. Variable: & Nb. Patents & Nb. Patents \\
\hline$P M 2.5$ & $\begin{array}{c}-0.0077^{* *} \\
(0.0036)\end{array}$ & $\begin{array}{c}-0.071^{* * *} \\
(0.027)\end{array}$ \\
\hline$\hat{v}$ & & $\begin{array}{c}0.064^{* *} \\
(0.027)\end{array}$ \\
\hline NUTS-3 FE & YES & YES \\
\hline Country-Year FE & YES & YES \\
\hline Log likelihood & -56582.7 & \\
\hline Pseudo R2 & 0.96 & \\
\hline Replications & & 500 \\
\hline Clusters & 1196 & 1365 \\
\hline $\mathrm{N}$ & 13599 & 16380 \\
\hline
\end{tabular}

This table presents the results for the poisson fixed effects regression. Estimates are obtained for a sample including all NUTS-3 regions. The first column shows the results for poisson fixed effects regression without accounting for endogeneity of $P M 2.5$. The second column shows the poisson fixed effects results using control function approach by including firststage residuals $\hat{v}$. We do not include surface pressure as control variable since it is collinear with the fixed effects in the poisson regression. However, further robustness test show that surface pressure do not have a significant impact on first stage-results and, thus, should not matter for the final results. The standard errors reported in parentheses and are fully robust. For the poisson regression with the control function approach, standard errors are obtained by bootstrapping the 1356 NUTS-3 regions using 500 bootstrap replications.

${ }^{*} p<0.10,{ }^{* *} p<0.05,{ }^{* * *} p<0.01$ 
Table 15: Accounting for spatial and serial correlation

\begin{tabular}{|c|c|c|c|}
\hline \multirow[b]{2}{*}{ Dep. Variable: } & Clustered SE & $S E-$ Assumption 1 & $S E-$ Assumption 2 \\
\hline & Log(Patents) & Log(Patents) & Log(Patents) \\
\hline \multirow[t]{2}{*}{$P M 2.5$} & $-0.087^{* *}$ & $-0.087^{* *}$ & $-0.087^{* *}$ \\
\hline & $(0.036)$ & $(0.044)$ & $(0.042)$ \\
\hline NUTS-3 FE & YES & YES & YES \\
\hline Country-Year FE & YES & YES & YES \\
\hline Controls & YES & YES & YES \\
\hline $\mathrm{N}$ & 13671 & 13671 & 13671 \\
\hline
\end{tabular}

Estimations conducted for a conservative sample including all NUTS-3 regions. Column 1 shows second-stage baseline results with SE clustered at NUTS-3 in accordance with results in table 17. Column 2 and 3 show second-stage results with spatial heteroskedasticity and autocorrelation consistent SE in line with Conley (1999, 2010). Assumption 1 (2) assumes a spatial correlation range of 500 (1000) kilometers and a serial correlation range of 5 (10) years. Conley standard errors are computed using the Stata code provided by (Foreman, 2020).

${ }^{*} p<0.10,{ }^{* *} p<0.05,{ }^{* * *} p<0.01$

Table 16: Different thresholds for a low VC

\begin{tabular}{|c|c|c|c|c|c|c|c|c|}
\hline \multirow[b]{2}{*}{ Dep. Variable: } & \multicolumn{2}{|c|}{ Low $V C \leq p 10$} & \multicolumn{2}{|c|}{ Low $V C \leq p 15$} & \multicolumn{2}{|c|}{ Low $V C \leq p 20$} & \multicolumn{2}{|c|}{ Low $V C \leq p 25$} \\
\hline & Log(Patents) & $P M 2.5$ & Log(Patents) & $P M 2.5$ & Log(Patents) & $P M 2.5$ & Log(Patents) & $P M 2.5$ \\
\hline$P M 2.5$ & $\begin{array}{c}-0.10^{* *} \\
(0.047)\end{array}$ & & $\begin{array}{c}-0.088^{* *} \\
(0.043)\end{array}$ & & $\begin{array}{c}-0.10^{* * *} \\
(0.036)\end{array}$ & & $\begin{array}{c}-0.054^{*} \\
(0.028)\end{array}$ & \\
\hline Share Inversions & & $\begin{array}{c}3.70^{* * *} \\
(0.52)\end{array}$ & & $\begin{array}{c}3.67 * * * \\
(0.51)\end{array}$ & & $\begin{array}{c}3.66^{* * *} \\
(0.51)\end{array}$ & & $\begin{array}{c}3.70^{* * * *} \\
(0.51)\end{array}$ \\
\hline Share $p 10 \geq V C$ & & $\begin{array}{c}90.6 \\
(82.0)\end{array}$ & & & & & & \\
\hline Share $p 15 \geq V C$ & & & & $\begin{array}{c}181.1^{* * *} \\
(53.4)\end{array}$ & & & & \\
\hline Share $p 20 \geq V C$ & & & & & & $\begin{array}{c}255.6^{* * *} \\
(39.5)\end{array}$ & & \\
\hline Share $p 25 \geq V C$ & & & & & & & & $\begin{array}{c}279.7^{* * *} \\
(31.5)\end{array}$ \\
\hline NUTS-3 FE & YES & & YES & & YES & & YES & \\
\hline Country-Year FE & YES & & YES & & YES & & YES & \\
\hline Controls & YES & & YES & & YES & & YES & \\
\hline KP F-stat. & 26.5 & & 31.5 & & 44.9 & & 63.3 & \\
\hline Hansen J stat. P-Val & 0.15 & & 0.81 & & 0.78 & & 0.27 & \\
\hline $\mathrm{N}$ & 12924 & 12924 & 12924 & 12924 & 12924 & 12924 & 12924 & 12924 \\
\hline
\end{tabular}

Standard errors are reported in parentheses and clustered at the NUTS-3 level.

SE clustered at NUTS-3

${ }^{*} p<0.10,{ }^{* *} p<0.05,{ }^{* * *} p<0.01$ 
Table 17: Different thresholds for dropping low patenting NUTS-3 regions

\begin{tabular}{|c|c|c|c|c|c|c|c|c|}
\hline \multirow[b]{2}{*}{ Dep. Variable: } & \multicolumn{2}{|c|}{ No trimming } & \multicolumn{2}{|c|}{ Trim NUTS-3 at 5\% } & \multicolumn{2}{|c|}{ Trim NUTS-3 at $10 \%$} & \multicolumn{2}{|c|}{ Trim NUTS-3 at $15 \%$} \\
\hline & Log(Patents) & $P M 2.5$ & Log(Patents) & $P M 2.5$ & Log(Patents) & $P M 2.5$ & Log(Patents) & $P M 2.5$ \\
\hline$P M 2.5$ & $\begin{array}{c}-0.087^{* *} \\
(0.036)\end{array}$ & & $\begin{array}{c}-0.099^{* * *} \\
(0.036)\end{array}$ & & $\begin{array}{c}-0.14^{* * *} \\
(0.037)\end{array}$ & & $\begin{array}{c}-0.14^{* * *} \\
(0.036)\end{array}$ & \\
\hline Share Inversions & & $\begin{array}{c}3.78^{* * *} \\
(0.50)\end{array}$ & & $\begin{array}{c}3.65^{* * *} \\
(0.51)\end{array}$ & & $\begin{array}{c}3.27^{* * *} \\
(0.50)\end{array}$ & & $\begin{array}{c}3.24^{* * *} \\
(0.52)\end{array}$ \\
\hline Share low VC & & $\begin{array}{c}227.2^{* * *} \\
(40.3)\end{array}$ & & $\begin{array}{c}253.7^{* * * *} \\
(39.5)\end{array}$ & & $\begin{array}{c}258.6^{* * *} \\
(40.6)\end{array}$ & & $\begin{array}{c}259.5^{* * *} \\
(41.8)\end{array}$ \\
\hline NUTS-3 FE & YES & & YES & & YES & & YES & \\
\hline Country-Year FE & YES & & YES & & YES & & YES & \\
\hline Controls & YES & & YES & & YES & & YES & \\
\hline KP F-stat. & 42.5 & & 44.9 & & 39.0 & & 37.1 & \\
\hline Hansen J stat. P-Val & 0.50 & & 0.82 & & 0.70 & & 0.96 & \\
\hline $\mathrm{N}$ & 13671 & 13671 & 12984 & 12984 & 12267 & 12267 & 11699 & 11699 \\
\hline
\end{tabular}

SE clustered at NUTS-3

${ }^{*} p<0.10,{ }^{* *} p<0.05,{ }^{* * *} p<0.01$

Table 18: Different sample periods

\begin{tabular}{lccccc}
\hline \hline Dep. Variable: & Log(Patents) & Log(Patents) & Log(Patents) & Log(Patents) & Log(Patents) \\
\hline PM2.5 & $-0.10^{* * *}$ & $-0.097^{* * *}$ & $-0.16^{* * *}$ & $-0.16^{* * *}$ & $-0.14^{* * *}$ \\
& $(0.036)$ & $(0.034)$ & $(0.055)$ & $(0.047)$ & $(0.046)$ \\
\hline Period & $2001-2012$ & $2001-2011$ & $2001-2010$ & $2001-2009$ & $2001-2008$ \\
NUTS-3 FE & YES & YES & YES & YES & YES \\
Country-Year FE & YES & YES & YES & YES & YES \\
KP F-stat. & 44.9 & 46.5 & 18.3 & 23.0 & 24.9 \\
Hansen J stat. P-Val & 0.78 & 0.65 & 0.21 & 0.79 & 0.51 \\
N & 12924 & 11778 & 10659 & 9565 & 8475 \\
\hline \hline
\end{tabular}

SE clustered at NUTS-3

${ }^{*} p<0.10,{ }^{* *} p<0.05,{ }^{* * *} p<0.01$ 
Table 19: Patenting and weather controls

\begin{tabular}{|c|c|c|c|c|c|c|}
\hline Dep. Variable: & Log(Patents) & Log(Patents) & Log(Patents) & Log(Patents) & Log(Patents) & Log(Patents) \\
\hline $\log (P o p)$ & $\begin{array}{c}0.15 \\
(0.27)\end{array}$ & $\begin{array}{c}0.29 \\
(0.25)\end{array}$ & $\begin{array}{c}0.16 \\
(0.27)\end{array}$ & $\begin{array}{c}0.16 \\
(0.27)\end{array}$ & $\begin{array}{c}0.16 \\
(0.27)\end{array}$ & $\begin{array}{c}0.25 \\
(0.26)\end{array}$ \\
\hline Surface Pressure & $\begin{array}{l}-0.00020 \\
(0.00080)\end{array}$ & & & & & $\begin{array}{c}-0.000044 \\
(0.00100)\end{array}$ \\
\hline Surface Pressure ${ }^{2}$ & $\begin{array}{c}4.0 \mathrm{e}-10 \\
(4.0 \mathrm{e}-09)\end{array}$ & & & & & $\begin{array}{l}-5.9 \mathrm{e}-10 \\
(5.2 \mathrm{e}-09)\end{array}$ \\
\hline Relative humidity & & $\begin{array}{c}0.27 \\
(3.20)\end{array}$ & & & & $\begin{array}{l}0.031 \\
(3.31)\end{array}$ \\
\hline Relative humidity $^{2}$ & & $\begin{array}{l}0.027 \\
(2.26)\end{array}$ & & & & $\begin{array}{c}0.23 \\
(2.34)\end{array}$ \\
\hline Temperature & & & $\begin{array}{l}0.018 \\
(0.91)\end{array}$ & & & $\begin{array}{l}-0.19 \\
(1.13)\end{array}$ \\
\hline Temperature $e^{2}$ & & & $\begin{array}{c}0.0000082 \\
(0.0016)\end{array}$ & & & $\begin{array}{l}0.00040 \\
(0.0020)\end{array}$ \\
\hline Precipitation & & & & $\begin{array}{c}35.3 \\
(63.8)\end{array}$ & & $\begin{array}{c}50.1 \\
(70.2)\end{array}$ \\
\hline Precipitation $^{2}$ & & & & $\begin{array}{c}-2336.3 \\
(17437.3)\end{array}$ & & $\begin{array}{c}-6023.3 \\
(18345.3)\end{array}$ \\
\hline Wind speed & & & & & $\begin{array}{c}-0.0022 \\
(0.10)\end{array}$ & $\begin{array}{l}-0.035 \\
(0.11)\end{array}$ \\
\hline Wind speed ${ }^{2}$ & & & & & $\begin{array}{c}-0.014 \\
(0.014)\end{array}$ & $\begin{array}{l}-0.015 \\
(0.014)\end{array}$ \\
\hline NUTS-3 FE & YES & YES & YES & YES & YES & YES \\
\hline Country-Year FE & YES & YES & YES & YES & YES & YES \\
\hline F-stat. & 0.42 & 0.68 & 0.64 & 0.49 & 1.45 & 1.15 \\
\hline R-sq & 0.96 & 0.96 & 0.96 & 0.96 & 0.96 & 0.96 \\
\hline $\mathrm{N}$ & 13270 & 13399 & 13270 & 13270 & 13270 & 13152 \\
\hline
\end{tabular}

SE clustered at NUTS-3

${ }^{*} p<0.10,{ }^{* *} p<0.05,{ }^{* * *} p<0.01$ 
Table 20: Patenting and air pollution with individual weather controls

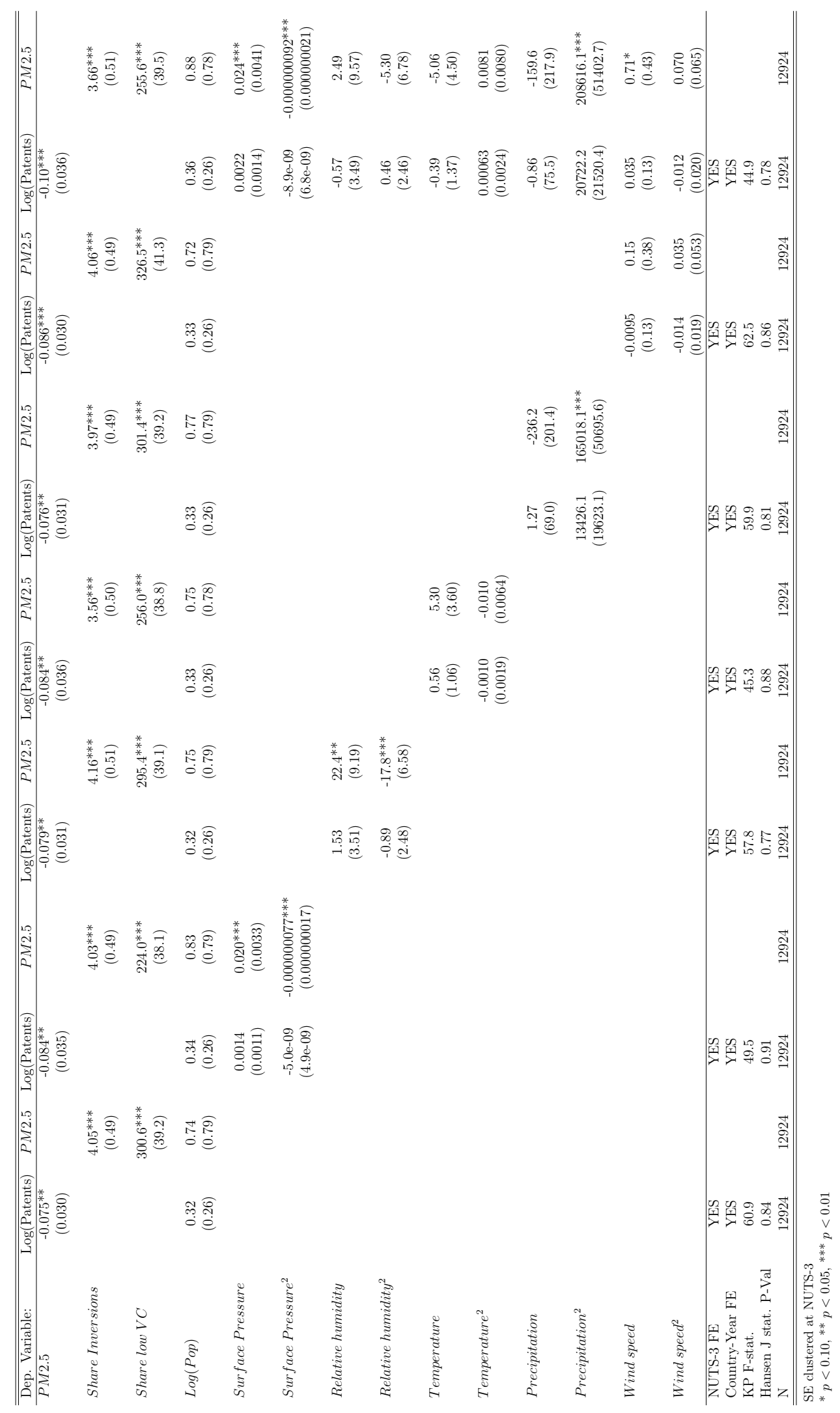




\section{F Data cleaning inventor relocation}

Morrison et al. (2017) provides a disambiguation of patent inventors. We assigning NUTS3 regions to corresponding goecodes of inventor addresses. Following, we trace relocation of inventors based on changes in NUTS-3 codes of patents inventors' filed in chronological order. Any address outside NUTS-3 regions are treated equally as "outside Europe" because we are not interested in movements between regions outside Europe. In some cases the history of filed patents stating the addresses for the individual inventor does not provide a clear relocation pattern. Specifically, the history of patents for an individual inventor shows frequent alternation between two or more NUTS-3 region within a short period. Such pattern are unlikely to reflect true relocations of inventors. One reason might be that inventors alternate between office and residence addresses for the patents they had filed. This issue is described in detail by Zacchia (2018) using the same dataset to trace the relocation of inventors. We follow his procedure to clean the data for unreasonable relocation patterns by assigning inventors to NUTS-3 regions in the following way:

1. We split the patent history of each inventor into temporal intervals, which are delimited by the years when a different NUTS-3 occurs for the first time

2. To each of these intervals we assign a unique NUTS-3 region by choosing the one that is observed most frequently

3. Ties are resolved conservatively in favor of the city that occurred earlier in the inventor's patent history 
CENTRE FOR ECONOMIC PERFORMANCE

Recent Discussion Papers

\begin{tabular}{|c|c|c|}
\hline 1816 & $\begin{array}{l}\text { Pedro Molina Ogeda } \\
\text { Emanuel Ornelas } \\
\text { Rodrigo R. Soares }\end{array}$ & $\begin{array}{l}\text { Labor unions and the electoral consequences } \\
\text { of trade liberalization }\end{array}$ \\
\hline 1815 & $\begin{array}{l}\text { Camille Terrier } \\
\text { Parag A. Pathak } \\
\text { Kevin Ren }\end{array}$ & $\begin{array}{l}\text { From immediate acceptance to deferred } \\
\text { acceptance: effects on school admissions and } \\
\text { achievement in England }\end{array}$ \\
\hline 1814 & $\begin{array}{l}\text { Michael W.L. Elsby } \\
\text { Jennifer C. Smith } \\
\text { Jonathan Wadsworth }\end{array}$ & $\begin{array}{l}\text { Population growth, immigration and labour } \\
\text { market dynamics }\end{array}$ \\
\hline 1813 & $\begin{array}{l}\text { Charlotte Guillard } \\
\text { Ralf Martin } \\
\text { Pierre Mohnen } \\
\text { Catherine Thomas } \\
\text { Dennis Verhoeven }\end{array}$ & $\begin{array}{l}\text { Efficient industrial policy for innovation: } \\
\text { standing on the shoulders of hidden giants }\end{array}$ \\
\hline 1812 & $\begin{array}{l}\text { Andreas Teichgräber } \\
\text { John Van Reenen }\end{array}$ & $\begin{array}{l}\text { Have productivity and pay decoupled in the } \\
\text { UK? }\end{array}$ \\
\hline 1811 & $\begin{array}{l}\text { Martin Beraja } \\
\text { Andrew Kao } \\
\text { David Y. Yang } \\
\text { Noam Yuchtman }\end{array}$ & AI-tocracy \\
\hline 1810 & $\begin{array}{l}\text { Ambre Nicolle } \\
\text { Christos Genakos } \\
\text { Tobias Kretschmer }\end{array}$ & $\begin{array}{l}\text { Strategic confusopoly evidence from the UK } \\
\text { mobile market }\end{array}$ \\
\hline 1809 & $\begin{array}{l}\text { Matthew D. Adler } \\
\text { Paul Dolan } \\
\text { Amanda Henwood } \\
\text { Georgios Kavetsos }\end{array}$ & $\begin{array}{l}\text { "Better the devil you know": are stated } \\
\text { preferences over health and happiness } \\
\text { determined by how healthy and happy people } \\
\text { are? }\end{array}$ \\
\hline 1808 & $\begin{array}{l}\text { Raphael Calel } \\
\text { Jonathan Colmer } \\
\text { Antoine Dechezleprêtre } \\
\text { Matthieu Glachant }\end{array}$ & Do carbon offsets offset carbon? \\
\hline
\end{tabular}




\begin{tabular}{|c|c|c|}
\hline 1807 & $\begin{array}{l}\text { Luke Milsom } \\
\text { Isabelle Roland }\end{array}$ & $\begin{array}{l}\text { Minimum wages and the China syndrome: } \\
\text { causal evidence from US local labor markets }\end{array}$ \\
\hline 1806 & $\begin{array}{l}\text { Matej Bajgar } \\
\text { Chiara Criscuolo } \\
\text { Jonathan Timmis }\end{array}$ & $\begin{array}{l}\text { Intangibles and industry concentration: } \\
\text { supersize me }\end{array}$ \\
\hline 1805 & $\begin{array}{l}\text { Luis Bosshart } \\
\text { Jeremiah Dittmar }\end{array}$ & $\begin{array}{l}\text { Pandemic shock and economic divergence: } \\
\text { political economy before and after the black } \\
\text { death }\end{array}$ \\
\hline 1804 & $\begin{array}{l}\text { Carlo Altomonte } \\
\text { Gianmarco Ottaviano } \\
\text { Armando Rungi } \\
\text { Tommaso Sonno }\end{array}$ & $\begin{array}{l}\text { Business groups as knowledge-based } \\
\text { hierarchies of firms }\end{array}$ \\
\hline 1803 & $\begin{array}{l}\text { Nikhil Datta } \\
\text { Stephen Machin }\end{array}$ & $\begin{array}{l}\text { Living wages and discontinuities for low- } \\
\text { wage workers }\end{array}$ \\
\hline 1802 & $\begin{array}{l}\text { Holger Breinlich } \\
\text { Dennis Novy } \\
\text { J.M.C. Santos Silva }\end{array}$ & Trade, gravity and aggregation \\
\hline 1801 & $\begin{array}{l}\text { Ari Bronsoler } \\
\text { Joseph Doyle } \\
\text { John Van Reenen }\end{array}$ & $\begin{array}{l}\text { The impact of healthcare IT on clinical } \\
\text { quality, productivity and workers }\end{array}$ \\
\hline 1800 & $\begin{array}{l}\text { Italo Colantone } \\
\text { Gianmarco Ottaviano } \\
\text { Piero Stanig }\end{array}$ & The backlash of globalization \\
\hline 1799 & $\begin{array}{l}\text { Jose Maria Barrero } \\
\text { Nicholas Bloom } \\
\text { Steven J. Davis }\end{array}$ & $\begin{array}{l}\text { Internet access and its implications for } \\
\text { productivity, inequality and resilience }\end{array}$ \\
\hline 1798 & $\begin{array}{l}\text { Nicholas Bloom } \\
\text { Tarek Alexander Hassan } \\
\text { Aakash Kalyani } \\
\text { Josh Lerner } \\
\text { Ahmed Tahoun }\end{array}$ & The diffusion of disruptive technologies \\
\hline
\end{tabular}

The Centre for Economic Performance Publications Unit

Tel: +44 (0)207955 7673 Email info@cep.lse.ac.uk

Website: http://cep.lse.ac.uk Twitter: @CEP_LSE 